\title{
Flood depth estimation by means of high-resolution SAR images and lidar data
}

\author{
Fabio Cian ${ }^{1}$, Mattia Marconcini ${ }^{2}$, Pietro Ceccato ${ }^{3}$, and Carlo Giupponi ${ }^{1}$ \\ ${ }^{1}$ Department of Economics, University of Venice Ca' Foscari, Venice, 30121, Italy \\ ${ }^{2}$ DFD German Aerospace Center (DFD-DLR), 82234 Weßling, Germany \\ ${ }^{3}$ International Research Institute for Climate and Society (IRI), Columbia University, New York, USA
}

Correspondence: Fabio Cian (fabio.cian@unive.it)

Received: 29 May 2018 - Discussion started: 29 June 2018

Revised: 19 October 2018 - Accepted: 6 November 2018 - Published: 19 November 2018

\begin{abstract}
When floods hit inhabited areas, great losses are usually registered in terms of both impacts on people (i.e., fatalities and injuries) and economic impacts on urban areas, commercial and productive sites, infrastructures, and agriculture. To properly assess these, several parameters are needed, among which flood depth is one of the most important as it governs the models used to compute damages in economic terms. This paper presents a simple yet effective semiautomatic approach for deriving very precise inundation depth. First, precise flood extent is derived employing a change detection approach based on the normalized difference flood index computed from high-resolution synthetic aperture radar imagery. Second, by means of a high-resolution lidar digital elevation model, water surface elevation is estimated through a statistical analysis of terrain elevation along the boundary lines of the identified flooded areas. Experimental results and quality assessment are given for the flood that occurred in the Veneto region, northeastern Italy, in 2010. In particular, the method proved fast and robust and, compared to hydrodynamic models, it requires sensibly less input information.
\end{abstract}

\section{Introduction}

Climate science foresees a future in which extreme weather events could happen with increased frequency and strength as a consequence of anthropogenic activities. Specifically, climate change would favor extreme precipitations, which could cause riverine, flash, and coastal floods (i.e., the main source of losses in the world as reported by NatCatSERVICE, 2015) to occur more and more often. The higher prob- ability of these events to happen is also exacerbated by landuse change and in particular, by settlement growth, which increases soil sealing and hence water runoff. The ultimate consequence would be an increase in fatalities and injuries, but also in economic losses in urban areas, commercial and productive sites, infrastructures, and agriculture.

Flood risk and impacts are not sufficiently understood and documented and need to be monitored systematically with improved precision as underlined by the European Union Floods Directive (European Commission, 2007). This is particularly important to support climate change adaptation policies as well as to develop robust public disaster relief funds, risk profiles for financial institutes, risk portfolios for reinsurance companies, and profiles of risk in supply chain for multinational companies (Mysiak, 2013; Desai et al., 2015). In order to assess flood impacts, in addition to their extent, several other parameters, such as flow velocity, debris factor, and inundation depth, shall be monitored during the event. Here, flood depth is particularly important since it governs the damage functions (or vulnerability curves or loss functions), which define the expected loss given a certain flood depth (Mojtahed, 2013; Scorzini, 2017).

Therefore, in ex post assessment deriving flood depth is essential to quantify impacts and damages, to better characterize flood risk, and to implement disaster risk reduction measures. Furthermore, it also has a key role in supporting emergency response, assessing accessibility and designing suitable intervention plans, calculating water volumes, allocating resources for water pumping, and rapidly estimating the costs for intervention and reconstruction. 
In Veneto, northeastern Italy, several floods caused major damage in the past decade, for example the one that occurred in 2010 in the city of Vicenza and its surroundings, which was the most serious in the area over the last 50 years (ARPAV, 2010). Moreover, extreme weather events are expected to increase in the future due to climate change (Zollo et al., 2015) in the entire region, and thus there is a great interest in monitoring floods.

To this purpose, remote sensing and in particular synthetic aperture radar (SAR) data have been playing an important role for decades, allowing, during crises, the derivation of flood extent maps like those provided by the European Copernicus Emergency Management Service (Copernicus EMS) or the International Charter on Space and Major Disaster (International Charter) (Martinis, 2015). In fact, SAR sensors are particularly suitable for this task due to their capability of observing through clouds (thanks to microwaves' all-weather capabilities) and at night (having their own source of illumination). Moreover, water surfaces are generally characterized by a very low backscattering (the portion of the outgoing radar signal that the target redirects directly back towards the radar antenna) due to the specular reflection of microwaves (O'Grady et al., 2011), hence making water mapping relatively easy. SAR data at high spatial resolution are continuously acquired by many satellites in low Earth orbits, such as the German TerraSAR-X (TSX), the Italian COSMO-SkyMed (CSK) and more recently the ICEYE and the ESA Sentinel-1 (S1) constellations. These sensors can provide images up to a resolution of a fraction of a meter (e.g., TSX, CSK) and are able to promptly monitor disaster within a few hours from their occurrence (e.g., CSK in urgent mode activation). However, up to now only the S1 constellation provides free, global, and constant acquisition. ICEYE acquires globally and constantly but its data are not freely accessible; the images acquired by TSX and CSK are also not freely accessible and in addition not even acquired systematically at a global scale.

Several types of algorithms have been developed to map floods using SAR data (Horritt 2001; Matgen et al., 2007; Brisco et al., 2011; Henry et al., 2006; Cossu et al., 2009; Martinis et al., 2015; Chini et al., 2012; Dasgupta et al., 2018; Giordan et al., 2018; Nico et al., 2000; Pierdicca et al., 2018). Among the most used, largely employed thresholding techniques aim at identifying a backscattering value below which a pixel is categorized as water. Specifically, such a threshold can be determined using automated procedures but it might consistently vary depending on environmental factors or the specific satellite acquisition geometry, for example (Giustarini et al., 2015; Henry, 2006; Martinis, 2009; Pierdicca, 2013). Another very common solution relies on the use of change-detection techniques, which compute the difference between an image acquired during the flood and one acquired before the event. In particular, flooded areas can be identified as they are associated with a decrease in the backscattering. On the one hand, this allows discrimination of permanent water bodies (mostly characterized by low and stable backscattering values) from temporary water surfaces; on the other hand, it might occur that land-cover changes associated with different backscattering values at the two considered time steps (as typically occurs for crops) can lead to overestimation of flooded areas (Giustarini, 2013, 2015; Long, 2014; Matgen, 2007).

The abovementioned approaches generally fail to detect floods occurring in vegetated areas where the water surface is obscured by tree branches and leaves. This might become a critical issue in regions characterized by a large amount of woodland and medium to tall vegetation and requires users to be extra vigilant to interpret the results. Furthermore, due to lack of details in medium-/low-resolution SAR data and to the multiple scattering and signal returns in high-resolution images, mapping flood in urban areas may be very difficult if not impossible (Schumann et al., 2011).

A new methodology (Cian et al., 2018), developed by the authors and also used in this work for deriving flood maps, is based on the use of the normalized difference flood index (NDFI). The index is based on the multi-temporal statistical analysis of two sets of images, one containing only the images before the event, and another one containing images both of the event and before the event. Through the computation of the NDFI, a change detection is performed, and flood maps are derived. The index highlights flooded areas and allows us to easily separate flooded pixels from non-flooded ones by means of a constant threshold.

Once the flood extent is derived, flood depth can be assessed using digital elevation models (DEMs). In this context, several approaches have been developed in the past from the 1980s. Gupta and Banerji (1985) used $60 \mathrm{~m}$ spatial resolution Landsat Multispectral Scanner (MSS) imagery to derive the water volume of a dam reservoir in the Himalayas and estimated the water level superimposing the boundary line of the water surface to a topographic map. About 10 years later, Oberstadler et al. (1996) employed $12.5 \mathrm{~m}$ resolution ERS-1 data for outlining the flood extent and overlaid the resulting map plotted with transparency to a map with topographic contours; next, water levels were manually registered at $500 \mathrm{~m}$ steps. Mason et al. (2001) derived the intertidal shoreline with ERS SAR data and estimated its height using a model based on depth-averaged hydrodynamics including the effects of tides and meteorological forcing. Matgen et al. (2007) used ENVISAT-ASAR multitemporal scenes and a lidar DEM (at 12.5 and $2 \mathrm{~m}$ resolution, respectively) to derive the water depth for the 2003 flood of the Alzette River in Luxembourg. Specifically, flood edges obtained from ASAR imagery were intersected with lidar data to estimate the elevation at the boundary line of water polygons. In particular, the water surface was computed using two different interpolation modeling techniques: triangulated irregular network (TIN) generation and multiple linear regression; then, the depth was calculated subtracting the DEM from the water elevation. This study was further improved 
by Schumann et al. (2007), who retrieved the water elevation combining the regression model with the TIN generation. Furthermore, the same methodology was also employed by Schumann et al. (2008) to compare the results obtained using different elevation information, namely topographic contours, the Shuttle Radar Topography Mission (SRTM) DEM, and a lidar-based DEM. The best results were obtained with $2 \mathrm{~m}$ resolution lidar data but good performances could be achieved even with the $90 \mathrm{~m}$ resolution SRTM DEM. Zwenzner and Voigt (2009) proposed a similar technique based on a model fitting the water elevation separately derived for the left and right riverbanks by combining the flood extent estimated from SAR data with DEM data. Here, to estimate the water level, a sequence of densely spaced river cross sections is shifted and adjusted individually.

All abovementioned approaches assume that the water level during the flood event is the same at both sides of the river cross section, thus assuming that the riverbanks are perfectly symmetric and that river flow and floodplain dynamics do not condition the overflow and the following stream. Nevertheless, while this hypothesis accounts for the river slope and defines an equilibrium condition at the ends of the cross section (i.e., they exhibit the same elevation), it may actually not fit many types of floods caused by riverbank ruptures, asymmetric river banks, or complex inundation dynamics, for example.

More recently, Huang et al. (2014) derived flood depth by combining Landsat and lidar data under the assumption that the water plane can be considered flat if the flooded area is sufficiently small. Accordingly, they split the flood extent map obtained from Landsat data into $750 \times 750 \mathrm{~m}$ squared tiles. Then, for each of them they "filled" the lidar DEM up to the level for which the resulting water extent was closest to the Landsat-based map (measured in terms of kappa coefficient; Cohen, 1968). For tiles completely covered by water, the average height of the eight neighbor tiles is taken. Finally, the water surface is calculated using an interpolation method (i.e., Kriging) and the depth computed as the difference with respect to the DEM. A similar approach was also presented by Matgen et al. (2016). Brown et al. (2016) derived a flood extent map from SAR using a semiautomated method (thresholding, manual interpretation, and correction). At $100 \mathrm{~m}$ intervals, elevation values along the flood edges were detected by means of a lidar. Elevation points were inspected, in certain cases corrected, or added manually by an operator in order to improve the water surface elevation estimation. The water surface was then created using flood depth maps from SAR images and DEMs derived with TIN interpolation (Cohen et al., 2018), for which the elevation of the flood water surfaces is estimated by a nearest-neighbor algorithm starting at the boundaries of flooded areas.

Instead, Iervolino et al. (2015) describe a model of SAR backscattering in case of flood (post event) and in case of no flood (pre-event). From the inversion of the model and the comparison between pre- and post-event conditions, they de- rive the flood depth. They propose two methods: (i) "singleimage object aware", which allows the estimation of the level of the water next to a building whose characteristics must be known (i.e., object aware), given that two gauges' measurements are available in its premises; and (ii) "two-image area aware", which uses a pre-event and a during/post-event image to retrieve the water levels for the whole area, using an unflooded area in the during/post-event image for calibration (i.e., area aware). Even though an interesting and promising approach, the two methods look complex and difficult to be implemented. Furthermore, ancillary data of difficult retrieval, such as data from gauge stations and information about buildings affected by the flood, are needed.

As already mentioned, flood depth is important not only for emergency response, but also for impact assessment. Purely economic works use flood depth (usually retrieved from third parties) for assessing direct and indirect impacts of floods by means of depth-damage functions. However, if flood depth information is not available, often the whole range of possible values is taken into account, hence resulting in extremely different scenarios. As an example, in Carrera et al. (2013) for a quite vast event $\left(1182 \mathrm{~km}^{2}\right)$ spreading all over northern Italy, a range in the depth from 1 to $6 \mathrm{~m}$ resulted in a damage estimate varying from EUR 4 billion to roughly EUR 10 billion. In a similar work, Amadio et al. (2016) could obtain precise estimate of the losses caused by the 2014 flood in Emilia Romagna, Italy, employing a simulated maximum flood depth computed by D'Alpaos et al. (2014) by means of hydraulic models. Nevertheless, this required some input information, as well as high processing power.

In this paper, a new methodology is proposed for rapid computation of flood depth by means of SAR data and a high-resolution DEM. Firstly, a flood map is derived from SAR data using the algorithm proposed in Cian et al. (2018). Secondly, a statistical analysis is performed on the terrain elevation values detected on the boundary lines of the flooded polygon to estimate the correct water elevation needed to compute the flood depth. The hypothesis is that all the detected water surfaces are flat and theoretically showing a constant elevation value along their boundaries. As explained in detail in Sect. 2, several sources of error make these values non-constant and the statistical analysis is a key step to estimate the correct water elevation.

The objective of this work is to present a semiautomatic, fast, and reliable method to estimate a precise flood depth in support of economic impact assessment methods for a rapid estimation of losses (and precise in case high-resolution elevation data are available) as well as the development of emergency plans. In contrast to many existing methods proposed in the literature, the presented method requires only two inputs (i.e., the flood extent map and a DEM), it is based on a simple yet precise algorithm, and it does not require intense manual interaction and strong computing capacity. Moreover, the algorithm is able to deal with uncertainties deriving from the flood extent map by means of statistical analysis and 


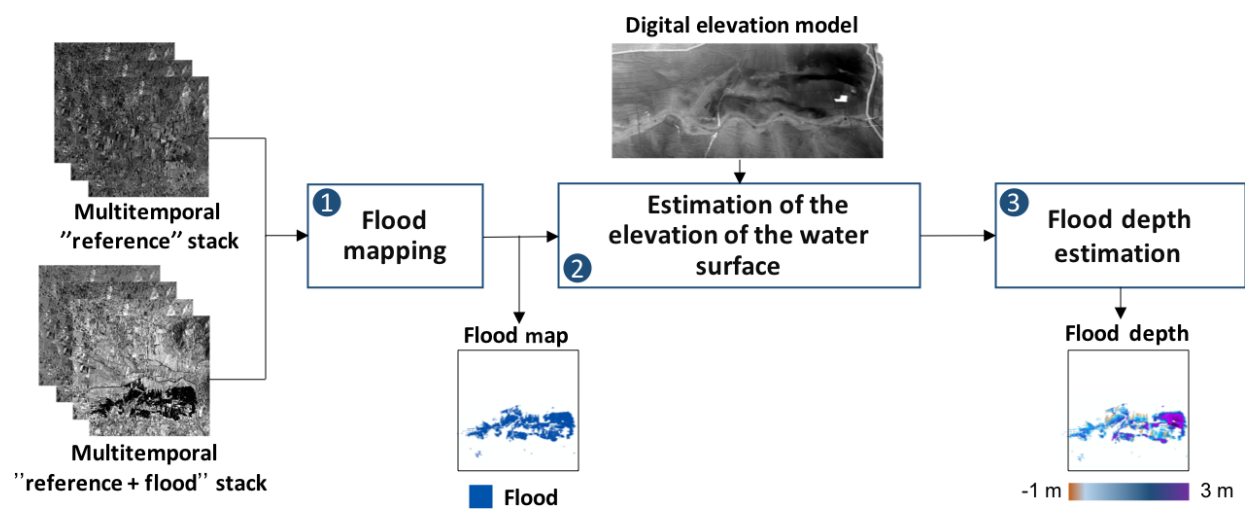

Figure 1. Flood depth estimation methodology: (1) flood maps are derived using the methodology presented in Cian et al. (2018); (2) by means of a high-resolution digital elevation model the elevation of the water surface is estimated, through a statistical analysis of elevation values along the boundary line of each flooded area; (3) flood depth is computed by subtracting the elevation values from the estimated elevation of water surface.

it is able to consider the change in elevation in different areas of the flood, in particular the variation in elevation along rivers, due to their natural slope.

In Sect. 2 the proposed methodology is given. Section 3 describes the data used in the experimental analysis and the investigated study area, while Sect. 4 presents the results obtained. In Sect. 5 quality assessment and discussion are reported, whereas conclusions are drawn in Sect. 6.

\section{Methodology}

The novel methodology proposed for estimating flood depth is composed of three main steps, namely (i) flood mapping (extent estimation), (ii) water surface elevation estimation, and (iii) flood depth estimation. They are explained in detail in the following three subsections.

\section{$2.1 \quad$ Flood mapping}

Flood mapping (block 1 in Fig. 1) is based on the use of the NDFI developed by the authors and explained in detail in Cian et al. (2018). The method is based on the multi-temporal statistical analysis of two stacks of SAR images: one containing only images before the flood, i.e., reference images ("reference" stack), and another one containing reference images and images of the event ("reference + flood" stack). The mean temporal backscattering for each pixel throughout the reference stack is computed together with the minimum backscattering value of each pixel throughout the reference + flood stack. The two statistics are used to derive the new NDFI, which is the normalized difference between the mean (reference) and the minimum (reference + flood) value. The computation of the NDFI corresponds to a change detection step. In fact, the index highlights flooded areas and allows us to easily separate flooded pixels from non-flooded ones by means of a constant threshold.
Therefore, in this step of the proposed system, after the computation of temporal statistics and of the NDFI index, a constant threshold on the NDFI value is applied $(\mathrm{NDFI}=0.7)$ to extract flooded areas. Following the methodology presented in Cian et al. (2018), three steps of postprocessing are applied to the resulting flood maps to reduce the effect of speckle and to reduce spurious flooded areas: (i) application of morphological filters (dilate and closing filter with a 3-by-3 pixel windows), (ii) exclusion of clusters smaller than 10 pixels, and (iii) exclusion of the pixels falling into a slope of $>5^{\circ}$ (where a flood would be unlikely). The final flood maps are used as input for block 2 (Fig. 1).

\subsection{Water surface elevation estimation}

In this step, we take as input the flood map previously generated and a high-resolution DEM of the area affected by the flood. The flood map is used to extract the boundaries of each flooded polygon to perform a statistical analysis of their elevation values by means of the DEM. Despite the fact that any DEM can be used in this methodology, it should exhibit a vertical resolution of a fraction of a meter to obtain significant flood depth values for economic impact assessment.

The objective of this step is to estimate the elevation of the water surface for each detected flooded polygon, analyzing the DEM elevation they exhibit along their boundaries. Similarly to Huang et al. (2014) and Brown et al. (2016), we suppose that the water surface of the flooded areas is flat. This can be considered a fair assumption in those cases in which the slope of the affected area is gentle and the velocity of the flood stream is modest. More precisely, we do not assume a single constant elevation value for the whole flood map, but a constant water elevation inside each detected flooded polygon, which thus allows taking into consideration the usual decrease in the water surface elevation along a river. Under this assumption, each polygon shall then exhibit a constant DEM elevation along its boundary, which corresponds to the 


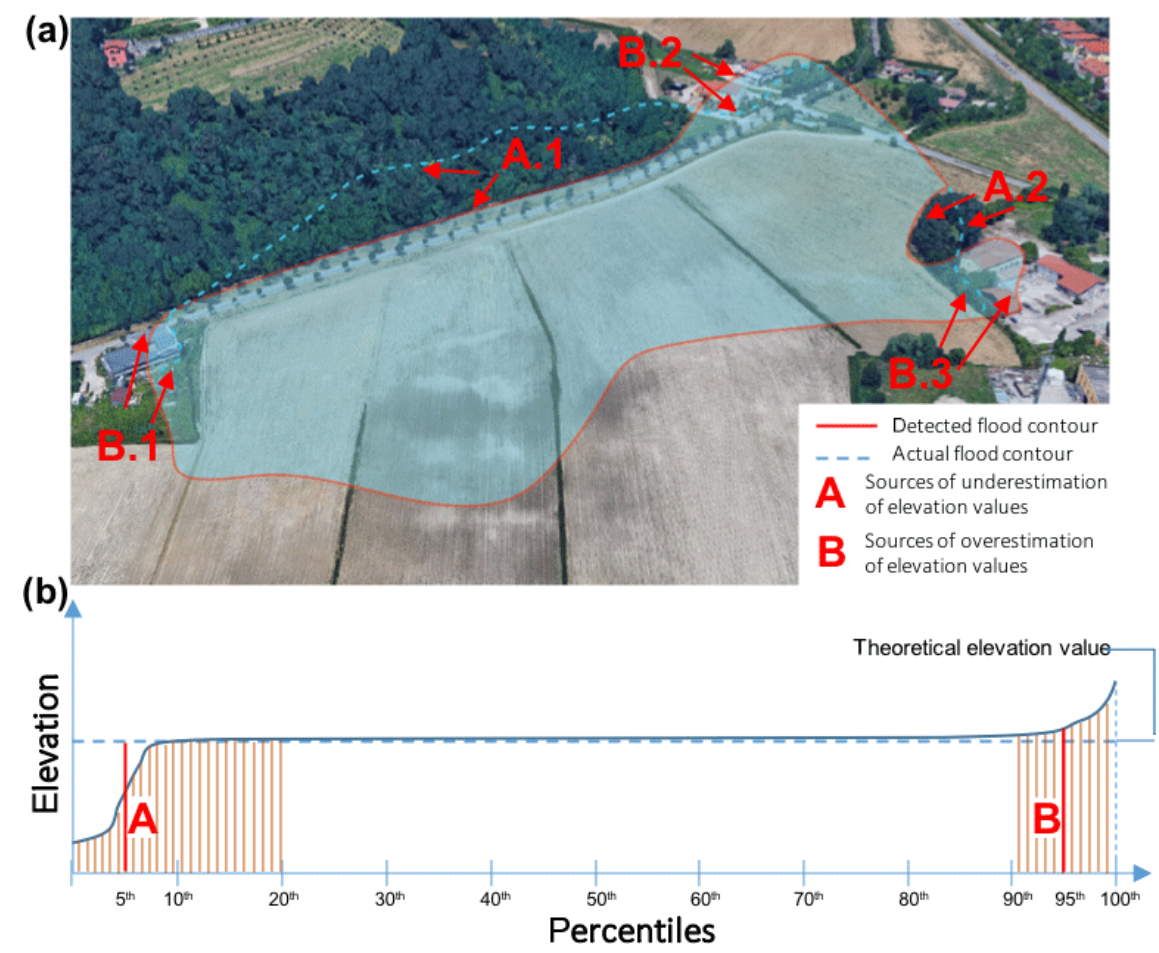

Figure 2. (a) Example of a detected flood polygon (light blue transparency) and relative flood boundary (red line). The dashed light blue line indicates the actual flood boundary, not correctly detected by the SAR-based flood map due to presence of vegetation obscuring the flood (cases indicated by the letter A) or due to radar shadow (cases indicated by the letter B). In the errors indicated by A, the elevation values detected are lower than the actual ones. Vice versa, in the errors indicated by B, the elevation values detected are higher than the actual ones. (b) Plot depicting the distribution function of the elevation along the boundary (red line). Areas indicated with A and B represent the values associated with the errors as explained above. The two threshold values (at the fifth and the 95th percentiles) are used to exclude outliers.

elevation of the entire water surface contained in the polygon itself; nevertheless, this is not happening due to different error sources.

Figure 2a shows an example of a detected flooded polygon (light blue transparency). Based on our theoretical assumptions, this water surface should have a constant elevation. In practice, this may not happen due to some sources of error (Fig. 2a). Specifically, the detected flood boundary (red line) may not correspond to the real boundary of the flood (dashed light blue line) due to (A) vegetation obscuring flooded areas leading to omission errors and (B) the nature of SAR images (speckle, radar shadow, layover; Franceschetti and Lunari, 2018) that can lead to false alarms or omission errors. Uncertainties in the SAR-based flood map, errors in the DEM, and misalignment between the SAR data and the DEM can lead to further uncertainty in the detection of elevation values along the boundary lines, resulting in outlier values under- or overestimating the real water elevation value. The plot reported in Fig. 2b shows the distribution (percentiles) of the DEM elevation values along the boundary lines. The abovementioned errors (over- or/and underestimation) can be associated with the values contained in areas A and B. It is more likely to find outliers on the lower end of the elevation value distribution since an underestimation is more likely due to the abovementioned sources of error.

Therefore, if we want to reliably estimate the correct water elevation for each flooded polygon, we need to identify and exclude outliers associated with omission errors (e.g., flood covered by vegetation) to commission errors (e.g., radar shadow included in the flood map) or misalignments between SAR and DEM data.

First, elevation values are extracted from the available input DEM in correspondence with the boundary of each flooded polygon individually. Then, the corresponding percentiles are computed (i.e., where a percentile denotes the value below which a given percentage of observations falls in the investigated group of observations) and values below the fifth and above the 95th percentiles are removed since, from extensive experimental analysis, this generally proved rather effective for removing under- and overestimation errors. The number of elevation points extracted depends on the length of the boundary of the flooded polygons and the horizontal resolution of the DEM. Using a high-resolution DEM (e.g., $1 \mathrm{~m}$ horizontal resolution) may result in thousands of points for boundaries several kilometers in length.

Next, given our hypothesis of a flat water surface, we have to check if the elevation value distribution is stable. Know- 
ing that locally we can find a non-stable distribution (due to the abovementioned sources of error), starting from $n=95$ we iteratively compute, with step 1 , the difference between the DEM value corresponding to the $n$th and the $(n-5)$ th percentile. If the difference is greater than $10 \mathrm{~cm}$, then the process continues; otherwise we stop and compute the water elevation as the mean value between the extremes of the fivepercentile interval analyzed at the last iteration. The idea is to identify a plateau in the distribution that can represent the correct water elevation.

We start looking for the correct elevation from the high end of the distribution for two reasons: (i) statistically there are fewer outliers on this side of the distribution and (ii) because it is the highest correct value of water elevation that determines the overall water elevation for the considered flooded polygon. The 95 th percentile represents a good starting point, able in most cases to exclude all the outliers present in one single polygon.

A step of five percentiles was found to be an optimal indicator of stability compared to the comparison of consecutive percentiles. This adaptive threshold takes care of the different conditions of each single polygon and allows an increase in the precision of the method. As expected, the statistical distribution of elevation values is not identical for each boundary line. Therefore, a fixed threshold would have led to and increased uncertainty in the final water surface elevation estimation, especially in those cases in which flood polygons have a non-regular geometry, which can overlap a complex topography or can encompass vegetation, roads, and built-up areas.

A threshold check is set on the 50th percentile, allowing us to spot possible wrong estimations. In fact, an elevation of the water surface below the 50th percentile indicates an exceptional behavior of the analyzed boundary line, which would need dedicated investigation.

The water surface elevation estimation step is carried out using a Python ${ }^{\mathrm{TM}}$ script including the ArcPy library. In this script, we provide as inputs the flood map (shapefile format) and the DEM (raster format). The DEM is clipped using the boundary line of a flood polygon by means of the ArcPy function ExtractByMask. Then, the elevation values of this newly created raster are analyzed and their distribution (percentiles) is computed. The procedure is repeated for each flooded polygon in the flood map, and the distribution values of each polygon are added in the attribute table of the shapefile. Finally, the algorithm selecting the optimal water elevation value is summarized by the following:

\subsection{Flood depth estimation}

Finally, depth is determined for each flooded pixel as the difference between its DEM value and the water elevation estimated for the corresponding flooded polygon.

In a few cases, in which the polygon geometry or the topography is non-regular, the estimation of the water level

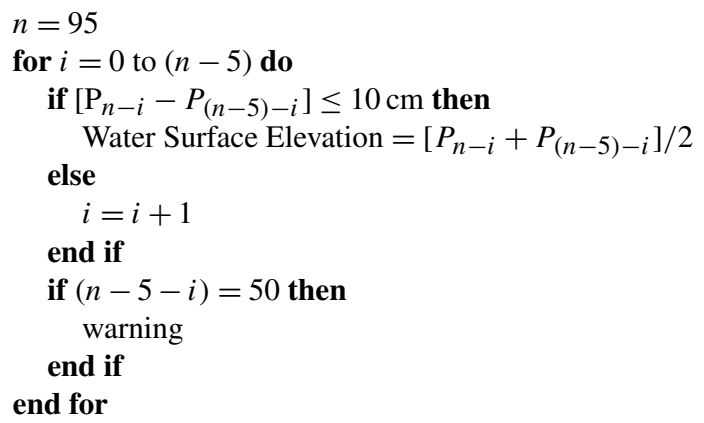

with $P$ indicating the percentile and $n$ the upper percentile threshold.

can be unprecise. However, if this is not yet detected by the threshold check, it can be easily detectable by analyzing at the resulting flood depth values. If inside a given polygon several negative values are obtained, this indicates an underestimation of the water elevation. Instead, if a given pixel is associated with a flood depth much higher than its neighbors, then the water level may have been overestimated. Therefore, we select the polygons showing unexpected behaviors and we compare them with a DEM-fill approach. The DEM is filled up to the estimated water surface elevation. If the resulting polygon extent does not match with the observed flooded polygon, we manually look for the elevation value that best approximated the flood extent and set it as the water elevation. Then we again compute the flood depth and reiterate the steps until we have a satisfying result.

\section{Data used and case study}

\subsection{Veneto flood 2010}

Heavy rain concurrent with other adverse effects from 31 October to 2 November 2010, in the Veneto region, northeastern Italy, led to the flooding of $140 \mathrm{~km}^{2}$ of land with major damage to properties and infrastructures. The event was originated by an Atlantic perturbation, which caused intense precipitation over the whole area, with extremes in the pre-Alps and piedmont areas. Local rainfall accumulation exceeded $500 \mathrm{~mm}$ and the average widely surpassed $300 \mathrm{~mm}$, leading to a serious hydraulic stress, especially in the area of Vicenza and the south of Padua. Sirocco wind, persistent on the sea and inland, slowed the discharge of rivers into the sea. Early snow melt due to the warm temperature also added water to the rainfall.

The first levee rupture in the study region occurred south of Vicenza in the afternoon of 1 November. Afterwards, the flood propagated southeast to Veggiano, where the embankments of the Bacchiglione River were broken in the night between 1 and 2 November. During 2 November the Bacchiglione banks also broke in the areas of Bovolenta, while 
Table 1. List of COSMO-SkyMed SAR data (Stripmap $3 \mathrm{~m}$ ) used for deriving flood maps of the event.

\begin{tabular}{llr}
\hline Date & Status & $\begin{array}{r}\text { Acquisition } \\
\text { time (UTC) }\end{array}$ \\
\hline 31 October 2008 & Reference & $17: 35$ \\
28 April 2010 & Reference & $17: 30$ \\
29 August 2010 & Reference & $05: 01$ \\
1 November 2010 & Flood & $05: 01$ \\
3 November 2010 & Flood & $17: 22$ \\
4 November 2010 & Flood & $18: 10$ \\
6 November 2010 & Flood & $17: 28$ \\
7 November2010 & Flood & $05: 13$ \\
\hline
\end{tabular}

the area of Saletto started to be flooded due to the rupture of the Frassine River banks in the same day (see Fig. 3). Based on the analysis of SAR imagery (Cian et al., 2018), in the area of Vicenza and Veggiano, the peak of the flood event was estimated between 2 November (northwest of frame A in Fig. 3) and 3 November (placeholder "A1" in Fig. 3). Instead, in the Bovolenta area (frame B in Fig. 3) the flood extent peak was reached on 4 November, with a consequent decrease in water levels in the following days. The area of Saletto reached a maximum flood extent on 3 November.

Figure 4 shows the measurements of hydrometers along the Bacchiglione River (hydrometers 1 to 5) and along the Frassine River (hydrometers 6 and 7) (ARPAV, 2010). We can notice how the flood wave moved from Vicenza (hydrometer 1) to Bovolenta (hydrometer 5), in accordance with the analysis of SAR data, which estimated the maximum extent after the highest measurement of the hydrometers. Concerning the Frassine River (hydrometers 6 and 7), we observe a similar behavior.

Overall 262 municipalities were affected, leading to roughly half a billion euros in damage, three fatalities, 3500 displaced people, and more the 500 thousand people affected. The flood also triggered hundreds of landslides in the mountainous surroundings, which led to more than 500 warnings of instability phenomena received by the province soil protection division (Floris et al., 2012; Scorzini, 2017). This paper analyses three main areas as shown in Fig. 3: Vicenza and its surroundings (A), the Bovolenta area at the south of Padua (B), and the Saletto area at the south of Euganei Hills (a group of hills of volcanic origin that rise to heights of 300 to $600 \mathrm{~m}$ a few kilometers south of Padua) (C).

\subsection{Data used}

Flood maps were derived using CSK data, provided by the Italian Space Agency, following the methodology proposed by Cian et al. (2018). Table 1 reports the complete list of scenes used.

Additionally, different DEMs were used for estimating the flood depth:
- the lidar digital terrain model (DTM) from the Venice Water Authority at $2 \mathrm{~m}$ resolution produced in 2004, which was employed for the Vicenza area of interest;

- the lidar DTM from the Italian Ministry of the Environment at $1 \mathrm{~m}$ resolution produced in 2012, which has been used for the areas of Bovolenta and Saletto;

- the $5 \mathrm{~m}$ resolution DTM available from the Veneto region geodatabase, which was used for the whole area of interest for the cross comparison with the hydrodynamic model.

To validate the results, in absence of proper ground truth, we made use of different datasets that allowed us a qualitative assessment of our maps.

- A simulation of the event by means of a hydrodynamic model, in which flood extent was estimated for 3 and 4 November using the 2DEF finite-element model (Viero et al., 2014) and flood depth was obtained as described by Viero et al. (2013). The simulation was computed in order to correspond to the exact moment of the SAR acquisition and it was performed using the DTM of the Veneto region at $5 \mathrm{~m}$ resolution.

- A set of aerial photographs acquired on 1 November taken by the Fire Department of Vicenza covering mainly the Vicenza area of interest was used.

- A set of in situ photographs taken from the Civil Protection Department on 1 and 2 November covering the area of Saletto was used.

- A set of in situ photographs taken by the authors in 2017 was used.

\section{Results}

\subsection{Elevation value distribution}

As discussed above, the proposed methodology is based on the statistical analysis of the elevation values along the boundary lines of the estimated flooded polygons. Figure 5 shows the distribution (percentiles) of elevation values for 18 randomly selected polygons in the Vicenza area of interest on 3 November. As discussed in Sect. 2, on the tails of the distribution (below the fifth percentile and above the 95th percentile) we can notice some irregularities, i.e., non-flat profiles, in contrast to more stable behaviors in most of the cases in the central part of the profiles. The thresholds on the fifth and 95th percentiles cut out most of the outliers. By means of the adaptive threshold starting from the 95th percentile, the method is able to estimate the elevation of the water surface looking for a plateau on the distribution. It prevents the overestimation of water elevation since it removes upper outliers, it prevents to underestimation by posing a limit on the lower 


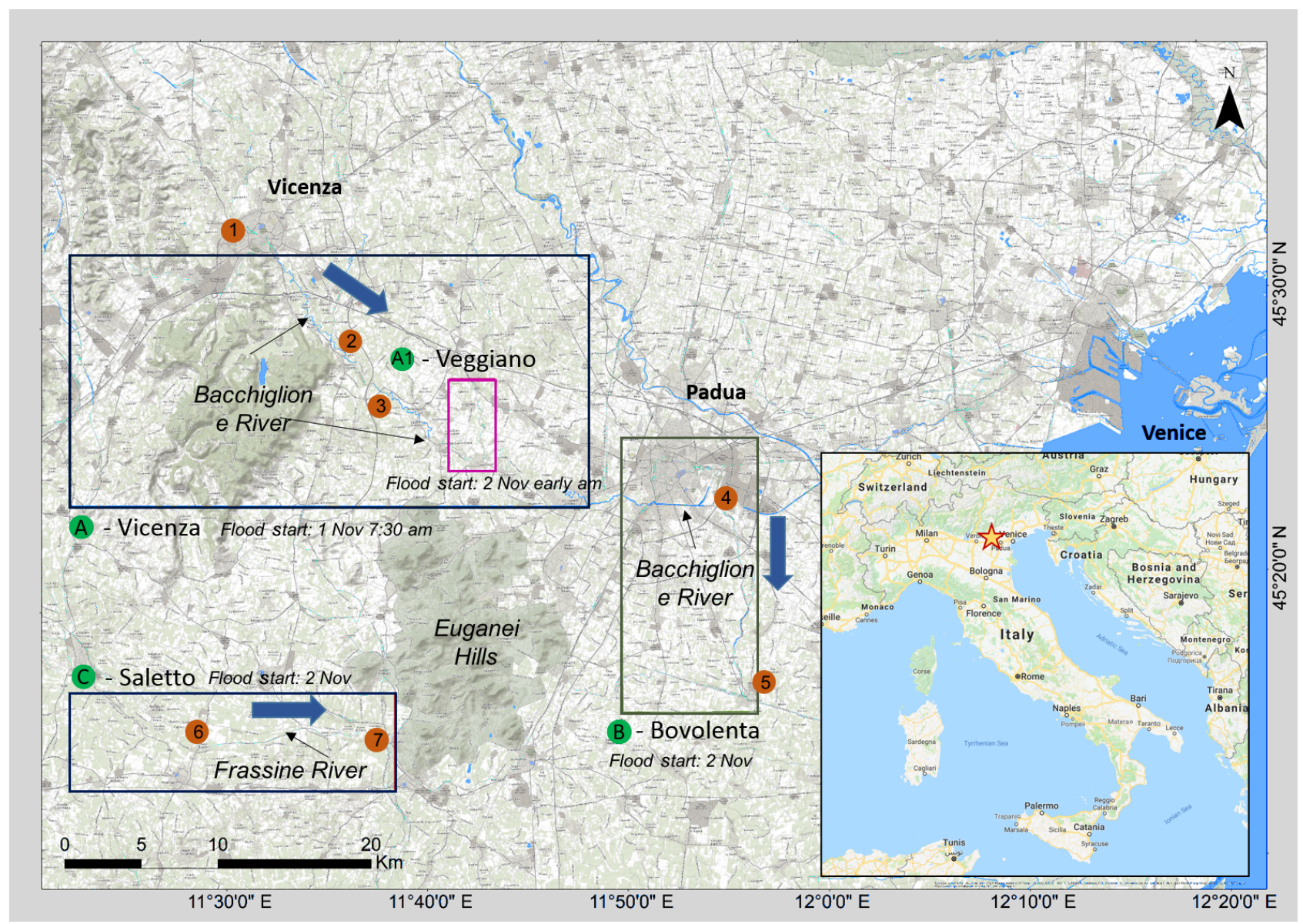

Figure 3. Overview of the area affected by the 2010 flood event that occurred in the Veneto region (Italy). The three main areas of interest are highlighted by the three frames: (A) Vicenza, (B) Bovolenta, and (C) Saletto. Placeholder A1 refers to the Veggiano area covered by the hydrodynamic modeling used for comparison purposes. The numbers in orange circles indicate the location of the hydrometers, whose measurements are reported in Fig. 4. For each frame the flood start date is reported along with the direction of the flood wave (blue arrows).

percentile and setting a condition on the slope of the profile (elevation difference equal to or lower than $10 \mathrm{~cm}$ in a step of five percentiles). Less regular profiles can be seen in the plot, like the one indicated by arrows A and B in Fig. 5. The irregularity is due to errors in the flood map, such as when vegetation obscures part of the flooded area, when there is a misalignment between the flood map and the DEM, when flooded polygons exhibit a non-regular geometry, or when the DEM along the flood boundaries has a complex topography. In these cases (less than $3 \%$ ), the proposed methodology might not result in reliable estimations. In fact, the elevation can exhibit two problems: (i) it never shows a stable value along the distribution (no plateau is found) and the water elevation is associated with the 50th percentile, and (ii) it presents a plateau at a higher elevation with respect to the real water surface elevation, resulting in an overestimation of the flood depth (this may rarely happen for example when the flood map crosses over roads or river banks at higher elevation due to inaccuracies of the flood map or misalignment between the flood maps and the DEM). The threshold check set at the 50th percentile detects the first problem, while the second is detected by looking at high value of flood depth $(>2 \mathrm{~m}$ ) or by finding discontinuities between neighboring polygons in the estimated surface water elevation. For those few cases, it is necessary to intervene manually as it is not possible to estimate the right elevation simply looking at this statistic, as described at the end of Sect. 2.

\subsection{Flood depth estimation}

Flood depth was computed for the three areas of interest indicated in Fig. 3. Flood depth was estimated for the whole flooded area except for a small portion of Veggiano area (a portion of the A.1 area indicated in Fig. 3), where lidar data were not available. Figure 6 shows the results for the Vicenza area of interest. Specifically, Fig. 6a shows the flood maps for 3 November and Fig. $6 \mathrm{~b}$ the lidar extent, which covers the entire flood with the exception of the central part of the map (the portion of the Veggiano area mentioned above). 


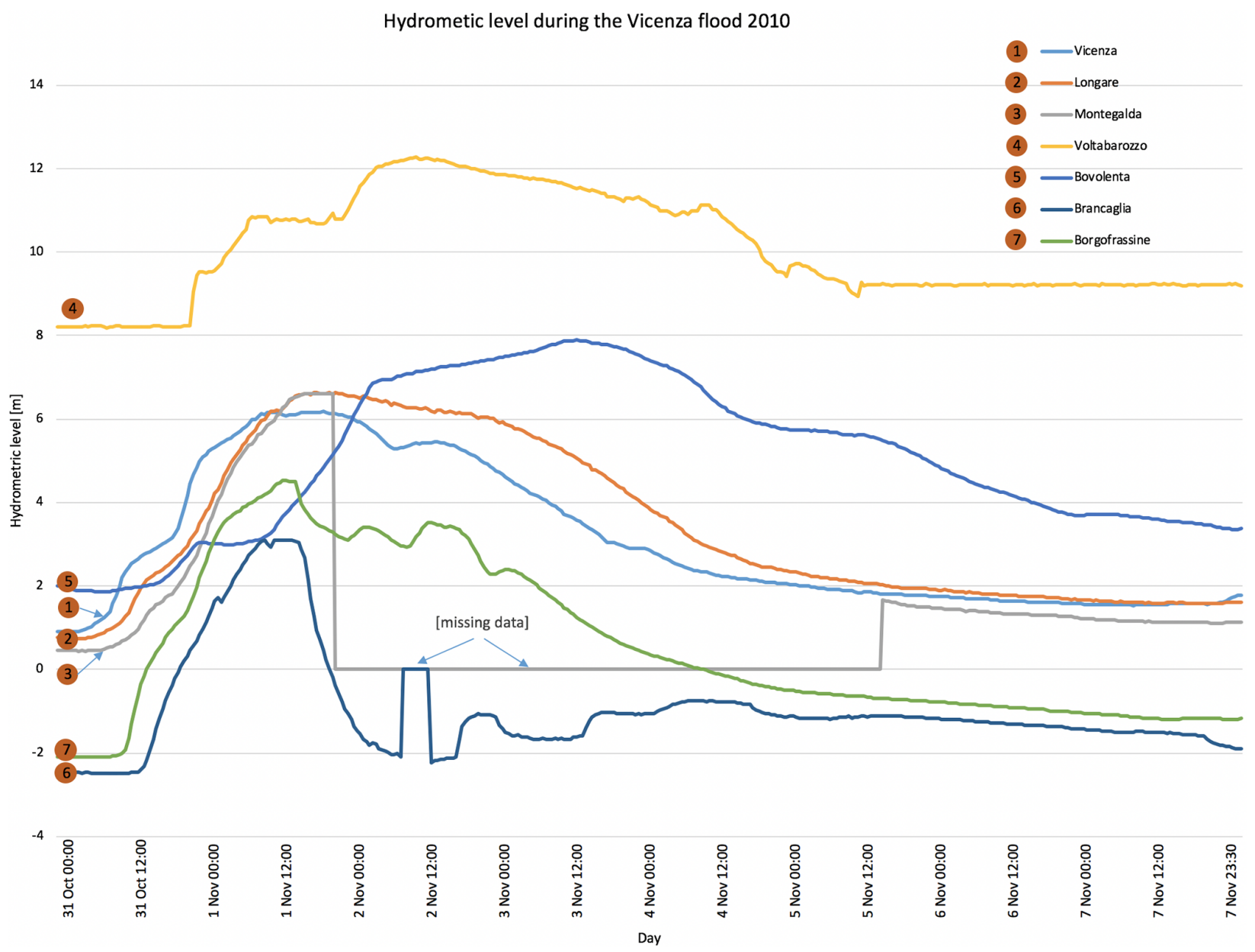

Figure 4. Measurements of hydrometers during the period of the investigated flood event. The flow of the Bacchiglione River (hydrometers 1 to 5) goes towards the southeast, i.e., from hydrometers 1 to 5. The flow of the Frassine River (hydrometers 6 and 7 ) goes towards the east, i.e., from hydrometers 6 to 7. In both cases, the measurements show the dynamic of the flood, which followed the stream of the river.

Figure $6 \mathrm{c}$ and e show, respectively, water surface elevation and flood depth for 3 November. Figure $6 \mathrm{~d}$ and $\mathrm{f}$ show water surface elevation and flood depth for 4 November. The dynamics of the event, i.e., the receding of water from 3 to 4 November, can be noticed where extent and depth of the flood decrease. The flooded area extends for several kilometers along the Bacchiglione River where the terrain elevation decreases gradually from the northwest to the southeast. Since we estimate water elevation for each single polygon, we are able to also take into consideration the slope of the river. This can be noted in the overall decrease in water surface elevation values in Fig. $6 \mathrm{c}$ and d.

For types of floods similar to this, the hypothesis of a flat water surface inside a single polygon is a good approximation since the flood evolution is slow and therefore water surface can be considered flat. This is especially true in the case of the Bovolenta and Saletto areas of interest where the flood extent was limited and the topography relatively simple.
Figure 7 shows the flood depth for the Bovolenta area of interest on (a) 4 and (c) 6 November. Also in this case, we can notice the receding of flood extent between the two dates. Figure $7 \mathrm{~b}$ and $\mathrm{d}$ show a zoom of the results, in which the high level of detail can be appreciated.

Figure 8 shows the results for the Saletto area of interest on (a) 3, (b) 4, (c) 6, and (d) 7 November. In this case, the evolution of the event, in particular the decrease in flood extent and depth is even clearer given the higher number of observations available.

As is evident from the depth maps and the relative scales, there can be negative values of flood depth, which in most of the cases occur at the proximity of the boundaries of flooded polygons. These most likely indicate an underestimation of the water surface elevation, even if false alarms in the flood map can also induce the same problem. However, the negative values are in most of the cases of the order of a few centimeters (less than $10 \mathrm{~cm}$ ) and these pixels can be considered very shallow water. 


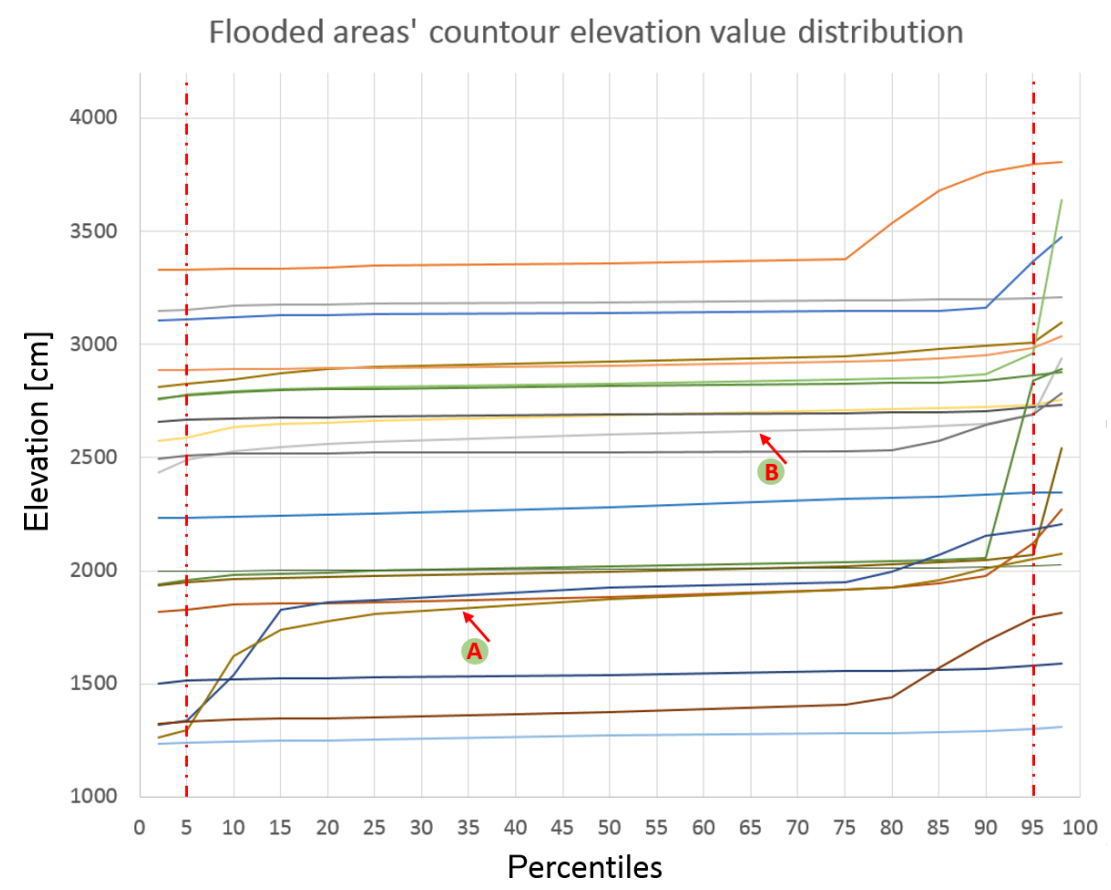

Figure 5. Elevation value distribution (percentiles) for a random selection of the flood polygon's boundaries in the Vicenza area on 3 November. The 95th and fifth percentile thresholds are highlighted. Arrows "A" and "B" indicate less regular profiles, for which the proposed methodology is less effective. In these cases (less than $3 \%$ of the total) a manual intervention is necessary.

\section{Assessment and discussions}

\subsection{Assessment with aerial photos}

Ground truth data consist of aerial photographs taken on 1 November right after the beginning of the event and of field pictures taken on 1 and 2 November by civil protection. Unfortunately, they do not match the dates and time of satellite acquisitions; therefore they cannot be used as a proper validation dataset. However, given the slow dynamic of the flood, they can provide very useful information about the water level, which can be estimated and compared with the results of our method and therefore provide an assessment of the results. To prove this, in Fig. 9 we show a comparison of flood extents derived for 2 November from $25 \mathrm{~m}$ resolution RADARSAT- 2 data and for 3 November from $5 \mathrm{~m}$ resolution CSK imagery. The lower resolution of RADARSAT- 2 does not allow extraction of the same level of detail of the map based on CSK data, but it is enough to show that the status of the flooded areas on the two consecutive days is very similar. Therefore, it makes sense to use the available aerial photographs for assessing the results, keeping in mind a possible change in the flood status between the two situations. In particular, from the image we can notice that for the Vicenza area (Fig. 9a and b) the flood receded from 2 to 3 November, while for the Saletto area (Fig. 9c and d) it expanded.

The assessment is carried out in three different steps: (1) estimation of water elevation corresponding to the dates of the aerial photos acquisition, (2) analysis of water elevation obtained using the proposed SAR-based method, and (3) cross comparison of the two values.

Concerning step 1, we made use of (i) a DEM-fill technique and (ii) data acquired during fieldwork in late 2017. DEM-fill consists of filling the DEM up to the elevation that gives a flood extent similar to the one displayed by the photos, which will be the estimated water elevation. In the fieldwork, we measured the height of the water plane on features recognizable in the aerial photos. These measurements added to the DEM value in the same location, allowing the estimation of water elevation. Averaging these two values allows the estimation of the water elevation at the moment of acquisition of the aerial photos, which can be compared with the results given by the proposed SAR-based method.

Concerning step 2, SAR-based results are analyzed in comparison with a DEM-fill method to understand the consistence of flood depth values in relation to the extent of DEM-based simulated flood.

Concerning step 3, the cross comparison is performed by comparing water elevation obtained in steps 1 and 2 .

The assessment was performed for the flood depth maps of 3 November, the date of the first high-resolution SAR image available after the acquisition of the aerial photos.

Panel I of Fig. 10 shows flood extent and depth (Fig. 10a) on 3 November at 17:22 UTC in the area of Ponti di Debba, south of the city of Vicenza, derived from the CSK SAR image shown in Fig. 10b. Panel II of Fig. 10 shows an aerial 


\section{Vicenza - water surface elevation and flood depth}
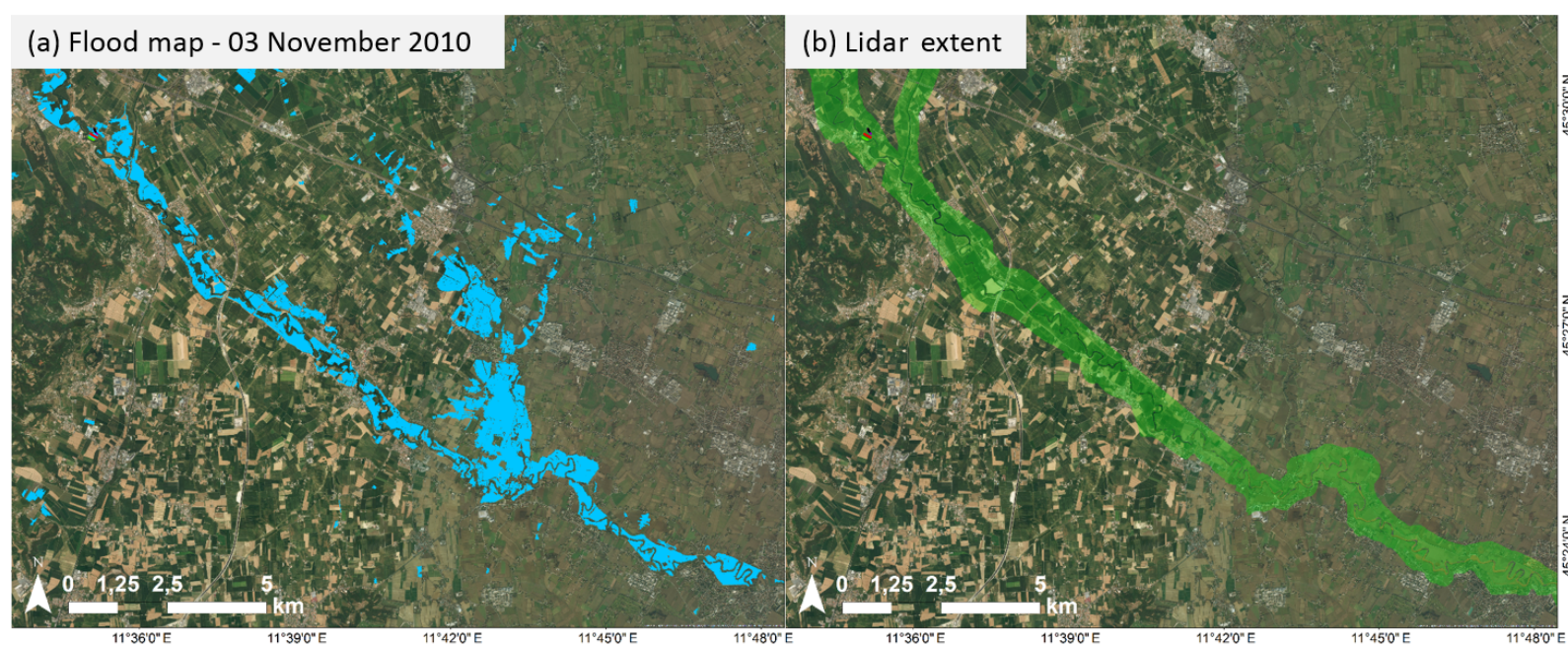

(c) Water surface elevation - 03 November 2010

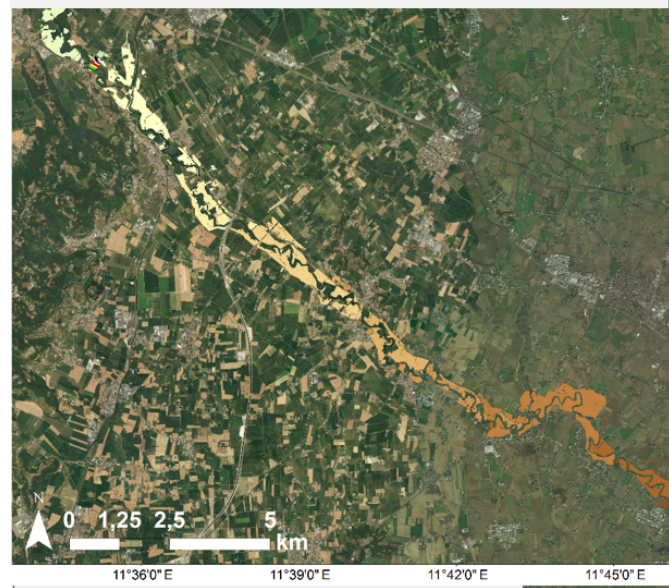

(d) Water surface elevation - 04 November 2010

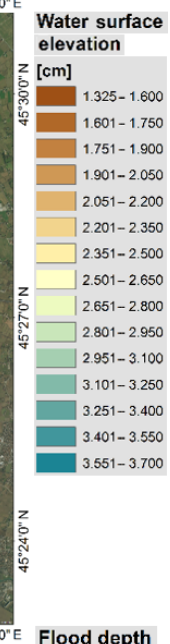

(e) Flood depth - 03 November 2010
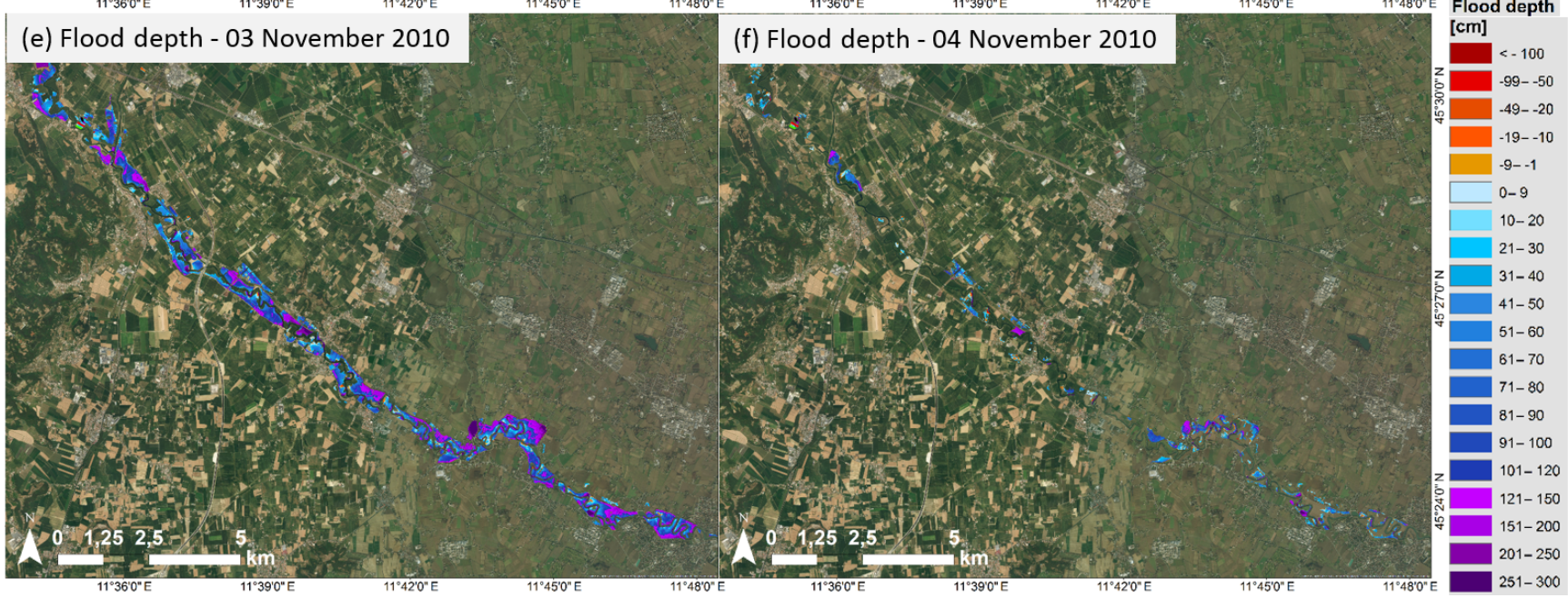

Figure 6. Water surface elevation and flood depth estimation for the Vicenza area of interest on 3 and 4 November. Panel (a) shows the flood map for 3 November and (b) the extent of the lidar data, which do not completely cover the flooded areas. Panels (c) and (d) show water surface elevation, and panels (e) and (f) show flood depth, respectively, for 3 and 4 November. Reddish values in (e) and (f) indicate negative flood depth and therefore an error in the estimation of the water surface elevation (underestimation). 


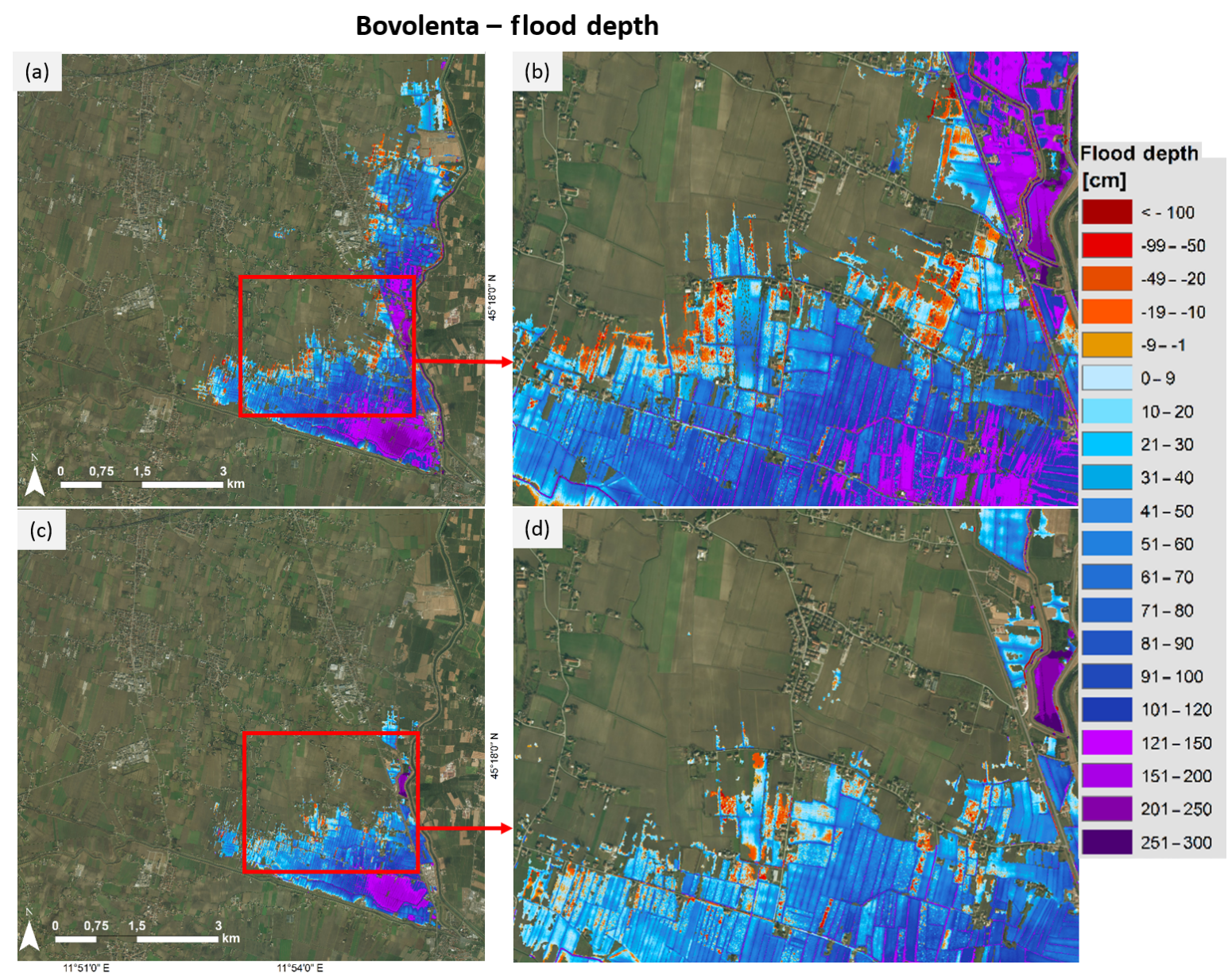

Figure 7. Flood depth for the Bovolenta area of study on (a) 4 November and (c) 6 November. Panels (b) and (d) show a zoom of the results, highlighting the high level of detail achievable. Reddish pixels represent the error in the water level estimation.

photo and fieldwork of the same area. Figure 10c shows the aerial photo acquired on 1 November at 14:00 UTC, in which three areas are highlighted: area 1 (zoom in 1.A) for which the proposed method detects no flood on 3 November and the DEM-fill method estimate of a water elevation of $28 \mathrm{~m}$; area 2 (zoom in 2.A) for which our method estimates a water level of $26.98 \mathrm{~m}$ and the fieldwork data $27.46 \mathrm{~m}(27.06 \mathrm{~m}$ elevation given by the DEM plus $0.4 \mathrm{~m}$ of flood depth estimated from fieldwork); area 3 (zoom in 3.A) for which our method detects no flood and the fieldwork data $27.45 \mathrm{~m} \mathrm{(27} \mathrm{m} \mathrm{eleva-}$ tion given by the DEM plus $0.45 \mathrm{~m}$ of flood depth estimated from fieldwork). Panel III of Fig. 10 shows the flood extent derived with the DEM-fill method for different water levels: Fig. 10d with a water level equal $26.98 \mathrm{~m}$ corresponding to the level estimated by our method; Fig. 10e with a water level equal to $27.45 \mathrm{~m}$, corresponding to the water level estimated by fieldwork data; and Fig. 10f with a water level equal to $28 \mathrm{~m}$, corresponding to the level estimated by the DEM-fill method in order to obtain the same flood extent of the aerial photo.
Figure 10f shows that with a water elevation of $28 \mathrm{~m}$, based on the DEM we obtain a very similar water extent of the one observed in the aerial photo. If we set a water level of $27.45 \mathrm{~m}$ (Fig. 10e), the value estimated from fieldwork, we would obtain a slightly underestimated flood extent compared to the one observed in the aerial photo. From this analysis, we can estimate a water level on 1 November of $27.72 \mathrm{~m}$ (average between 27.45 and $28 \mathrm{~m}$ ).

Looking at Fig. 10d, we can observe that the flood extent resulting with a water level of $26.98 \mathrm{~m}$, the same estimated with our method, is very similar to the extent extracted from the SAR image. A similar extent confirms the goodness of the SAR-based flood map, while the estimation of the water level, $26.98 \mathrm{~m}$, is comparable to the value estimated from the aerial photo and relative to 2 days before the SAR acquisition. This would mean a decrease in the water level of $0.74 \mathrm{~m}$ in 2 days. The reduction of flood extent in this area from 2 to 3 November is also confirmed by RADARSAT- 2 acquisition as we can see in Fig. 9a and b.

Panel I of Fig. 11 shows flood extent and depth (Fig. 11a) on 3 November at 17:22 UTC in the area of Via Isole, in 

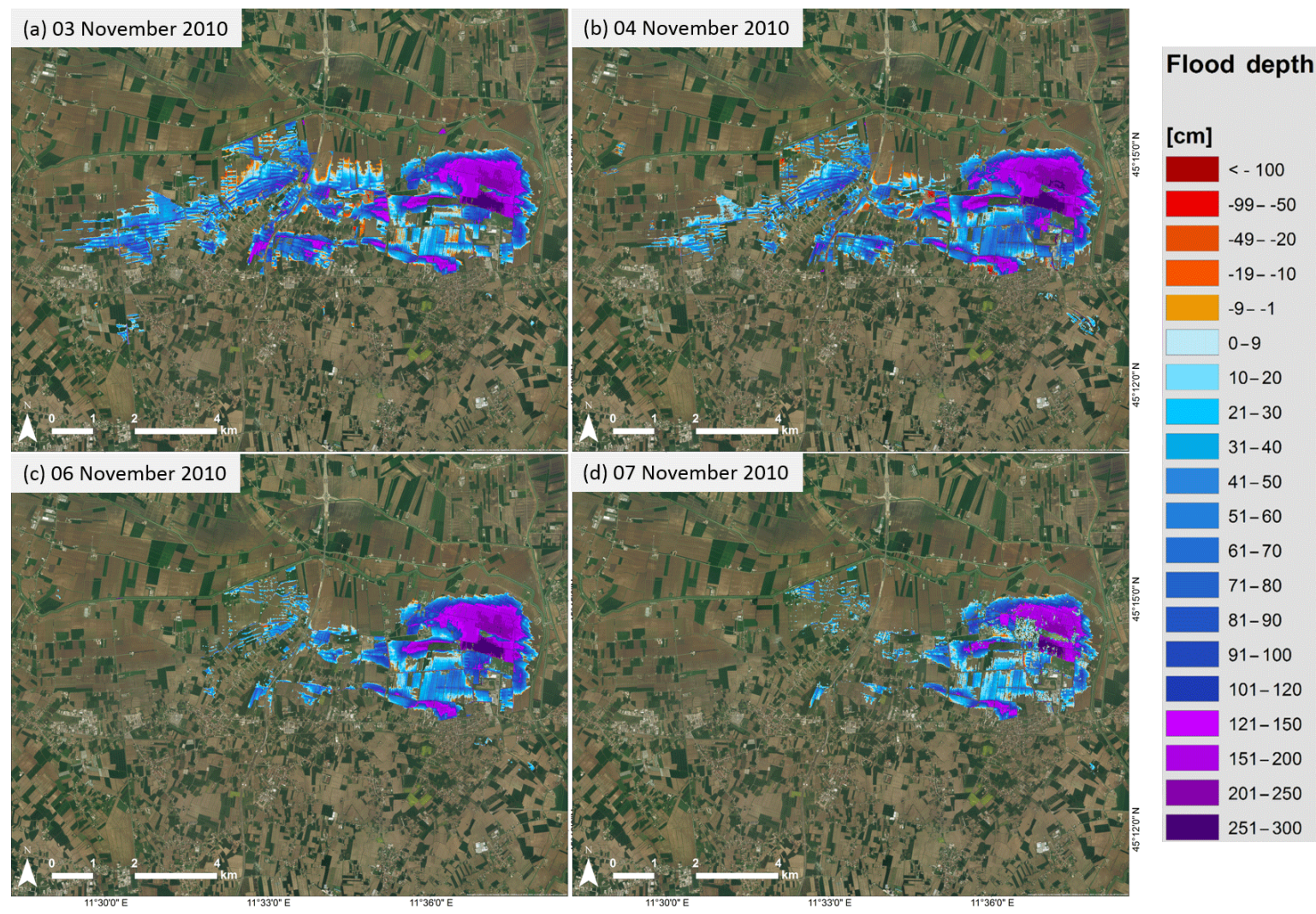

Figure 8. Flood depth for the area of interest of Saletto on (a) 3, (b) 4, (c) 6, and (d) 7 November.

the Saletto area, derived from the CSK SAR image shown in Fig. 11b. Panel II of Fig. 11 shows an aerial photo and fieldwork of the same area. Figure 11c shows the aerial photo acquired on 1 November at about 14:50 UTC, in which two areas are highlighted: area 1 (zoom in 1.A) for which the proposed method detects a water elevation of $11.6 \mathrm{~m}$, the DEMfill method estimates a water elevation of $11.4 \mathrm{~m}$, and the fieldwork data estimates $11.38 \mathrm{~m}(10.7 \mathrm{~m}$ elevation given by the DEM plus $0.68 \mathrm{~m}$ of flood depth estimated from fieldwork); area 2 (zoom in 2.A) for which the proposed method estimates a water elevation of $11.6 \mathrm{~m}$ and the fieldwork data $11.33 \mathrm{~m}$ ( $10.93 \mathrm{~m}$ elevation given by the DEM plus $0.4 \mathrm{~m}$ of flood depth estimated from fieldwork). Panel III of Fig. 11 shows the flood extent derived with the DEM-fill method for different water levels: Fig. 11d with a water level equal to $11.6 \mathrm{~m}$ corresponding to the elevation estimated by the proposed method; Fig. 11e with a water level equal to $11.38 \mathrm{~m}$, corresponding to the water elevation estimated by field work; Fig. 11f with water level equal to $11.4 \mathrm{~m}$, corresponding to the level estimated by the DEM-fill method in order to obtain the same flood extent of the aerial photo.

Figure 11f shows that with a water elevation of $11.4 \mathrm{~m}$, based on the DEM we obtain a water extent very similar to the one observed in the aerial photo. If we set a water level of $11.38 \mathrm{~m}$ (Fig. 11e), the value estimated from fieldwork, we obtain the same flood extent compared to the one observed in the aerial photo. From this analysis, we can estimate a water level on 1 November of $11.38 \mathrm{~m}$.

Looking at Fig. 11d, we can observe that the flood extent resulting with a water level of $11.6 \mathrm{~m}$, the same estimated with the proposed method, is very similar to the one observed in the SAR image.

Also in this case, an increase of $0.2 \mathrm{~m}$ from 2 to 3 November is consistent with the situation observed in SAR acquisitions as shown in Fig. 9c and d.

Buildings in the central north side of the image are categorized as flooded by the DEM-fill method in contrast to the SAR-based maps. It is worth noticing that SAR data do not allow extraction of flooded areas between buildings, where a mechanism of double bounce occurs, making the radar backscatter increase rather than decrease. However, we have no evidence that this specific area was actually flooded.

The same approach was followed for a total of 120 points distributed in the Vicenza (25 points) and Saletto areas of study (95 points) as shown in Fig. 12. These points were selected based on recognizable features in the aerial or fieldwork photos of 1 and 2 November. These points belonged to different flood polygons in the SAR-based flood map. For each point, we computed the difference between the water elevation estimated for 1 or 2 November based on aerial or 


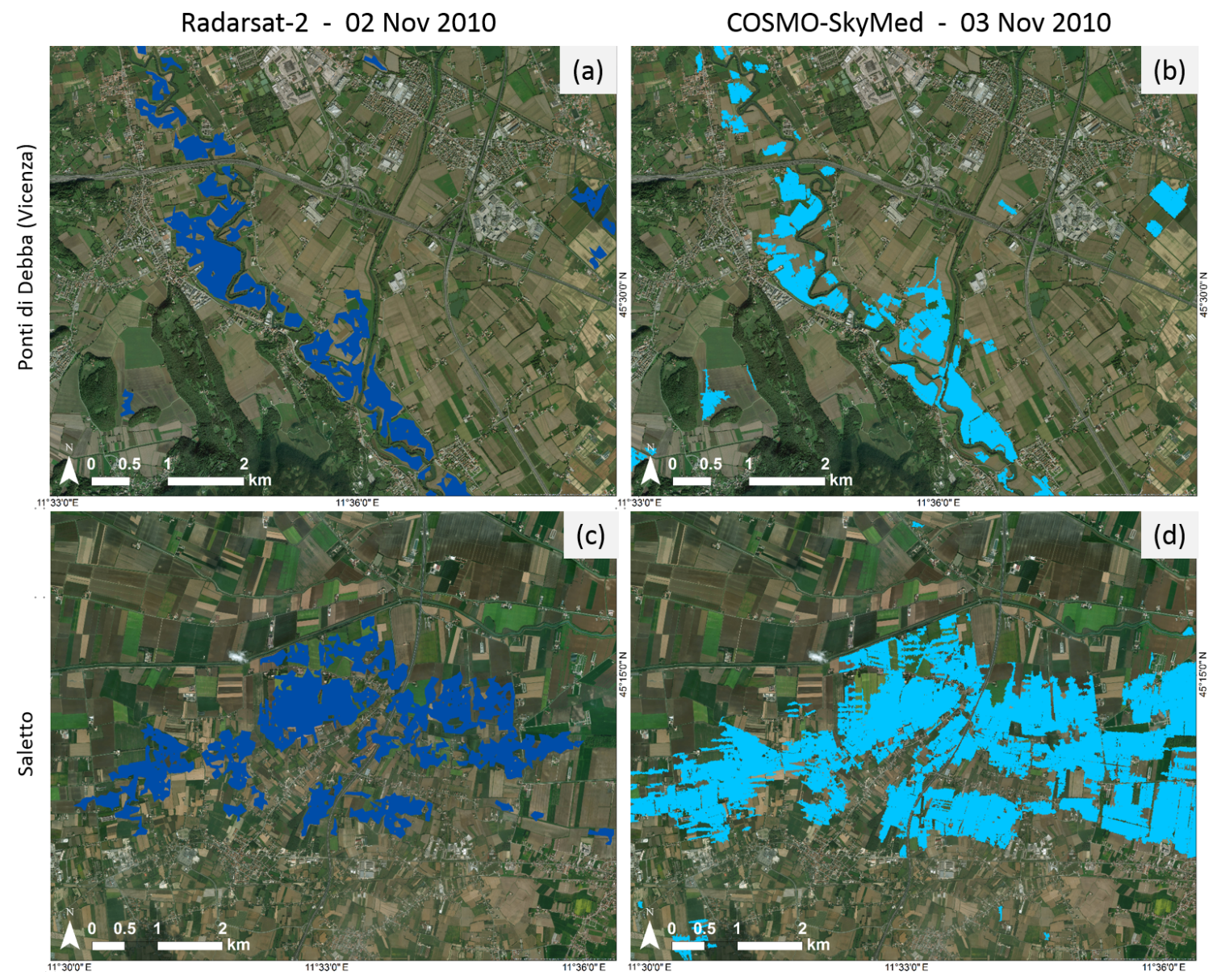

Figure 9. Comparison between RADARSAT-2 (2 November 2010) and COSMO-SkyMed flood maps (3 November 2010). RADARSAT-2 has a lower resolution $(25 \mathrm{~m})$ compared to COSMO-SkyMed $(5 \mathrm{~m})$, which provides a coarser flood map. We can see by the comparison of the two maps that the flood has a comparable extent on the two days. In particular, from the image we can notice that for the Vicenza area (Fig. 9a and b) the flood has receded from 2 to 3 November, while for the Saletto area (Fig. 9c and d) it has expanded.

fieldwork photos (step 1 of the assessment process) and the water elevation estimated from the SAR image for 3 November. For the area of Vicenza we obtained an average difference of $+53 \mathrm{~cm}$. This difference is consistent with the observed change of flood depth (decrease) from 1 and 3 November. For the area of Saletto we obtained an average difference of $-47 \mathrm{~cm}$, a value that is consistent with the increase in flood depth observed from 1 and November 3.

The differences are mainly due to the different timing of observation between the SAR image and the aerial and fieldwork photos. However, a source of errors is also intrinsic in the SAR method. In fact, we can have false alarms or a false negative in the flood map (overestimation of flood extent due to radar shadow, or flood underestimation due to vegetation on top of flood areas) or misalignment between the DEM and the SAR data, which could be a geolocation error or an effect of different resolutions between the two datasets.

\subsection{Cross comparison: hydrodynamic modeling}

Flood depth obtained with the presented methodology was compared with the one derived using the hydrodynamic model presented in Viero et al. (2013). The simulation was available for the area of Veggiano (area A1 in Fig. 3) and Bovolenta (area B in Fig. 3) on 3 and 4 November at the same time of the SAR acquisitions over the same areas. It made use of the DTM at $5 \mathrm{~m}$ resolution of the Veneto region geodatabase; therefore the same DTM has been used with the proposed methodology to derive meaningful results for comparison.

The first row of panels in Fig. 13 shows the simulated flood depth (a), the SAR-based estimated flood depth (b), and the difference between the two (c) for the Veggiano area on 3 November 2010. The second row, Fig. 13d-f, shows the same series of results for the same area on 4 November. The third row, Fig. 13g-i, shows the same series of results for the Bovolenta area on 4 November. 

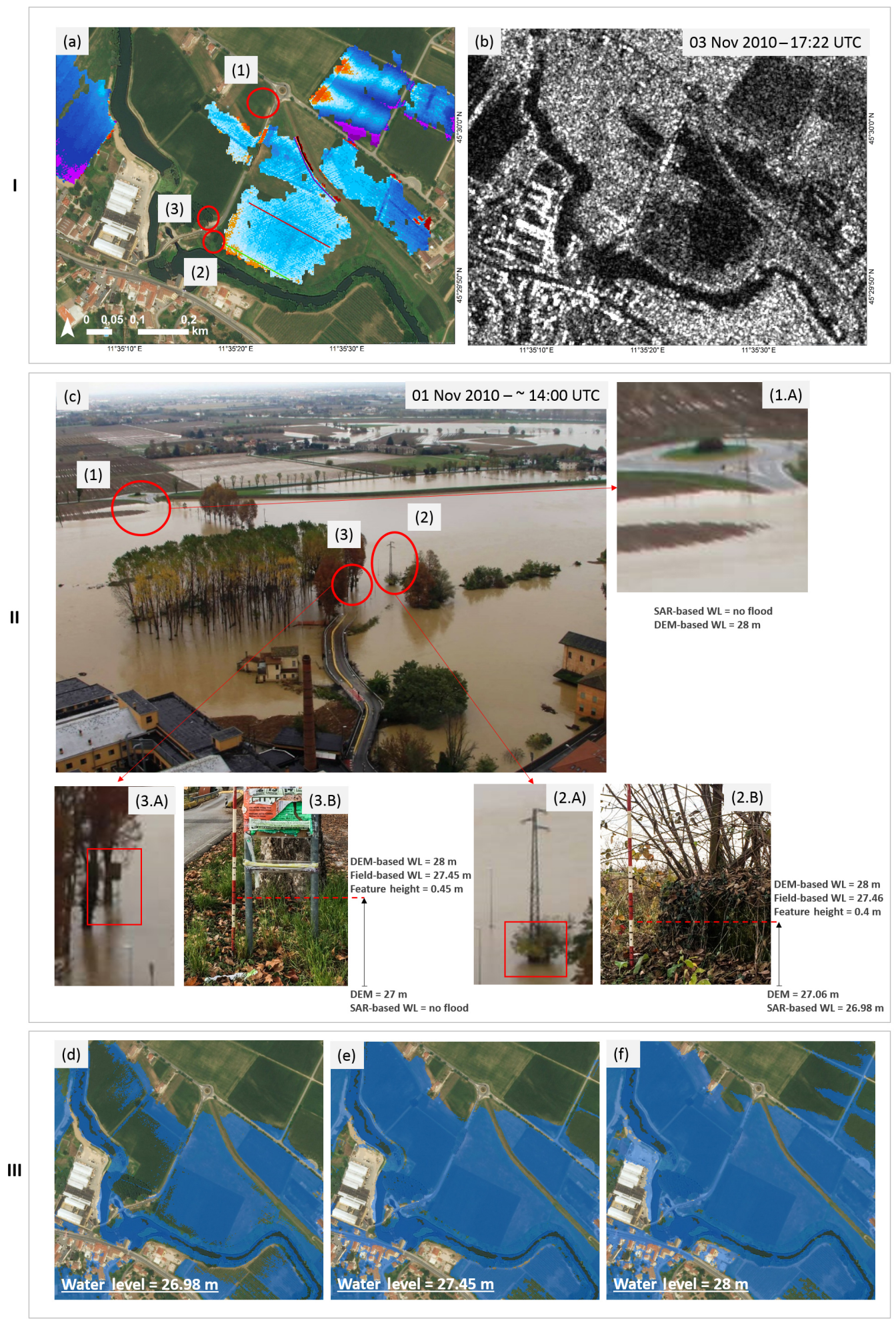

Figure 10. Flood depth on 3 November over Ponti di Debba in the Vicenza area of interest; panel I shows (a) flood depth in the area analyzed; (b) CSK image acquired on 3 November at 17:22 UTC from where the flood map has been derived; panel II shows (c) an aerial view of the event acquired on 1 November at about 14:00 UTC with zooms on three areas (1.A, 2.A, 3.A) with relative fieldwork images (2.B and 3.B); panel III shows the flood extent derived with the DEM-fill method for different water levels: (d) with a water level equal to $26.98 \mathrm{~m}$ corresponding to the level estimated by the proposed method; (e) with a water level equal to $27.45 \mathrm{~m}$ corresponding to the water level estimated by fieldwork data; (f) with a water level equal to $28 \mathrm{~m}$ corresponding to the level estimated by the DEM-fill method in order to obtain the same flood extent of the aerial photo. 

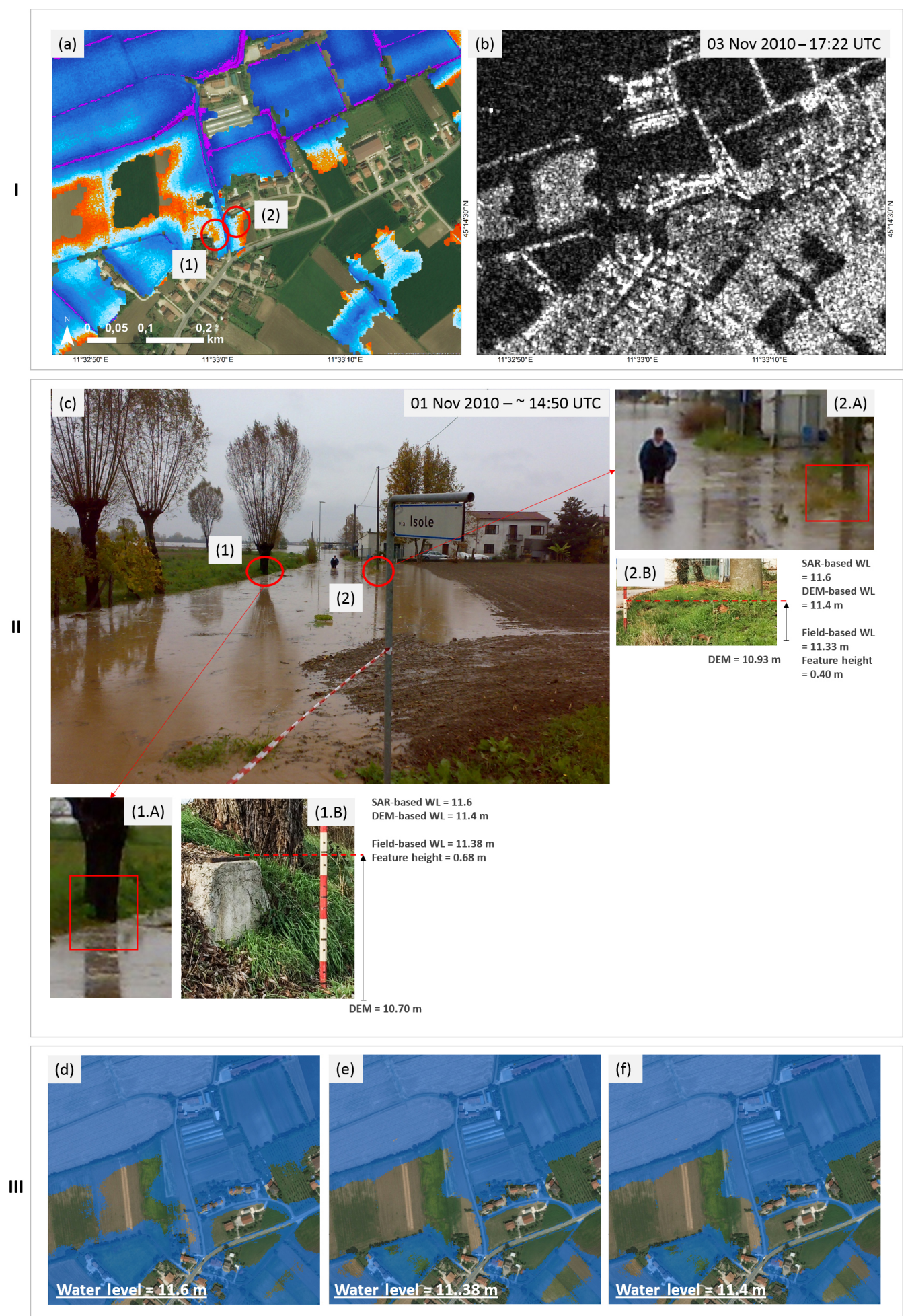

Figure 11. Flood depth on 3 November over Via Isole in the Saletto area of interest; panel I shows (a) flood depth in the area analyzed; (b) CSK image acquired on 3 November at 17:22 UTC from where the flood map has been derived; panel II shows (c) an aerial view of the event acquired on 1 November at about 14:50 UTC with zooms on two areas (1.A, 2.A) with relative fieldwork images (2.B and 3.B); panel III shows the flood extent derived with the DEM-fill method for different water levels: Fig. $11 \mathrm{~d}$ with a water level equal to $11.6 \mathrm{~m}$ corresponding to the elevation estimated by the proposed method; Fig. 11e with a water level equal to $11.38 \mathrm{~m}$ corresponding to the water elevation estimated by fieldwork for area 1; Fig. 11f with a water level equal to $11.4 \mathrm{~m}$ corresponding to the level estimated by the DEM-fill method in order to obtain the same flood extent of the aerial photo. 


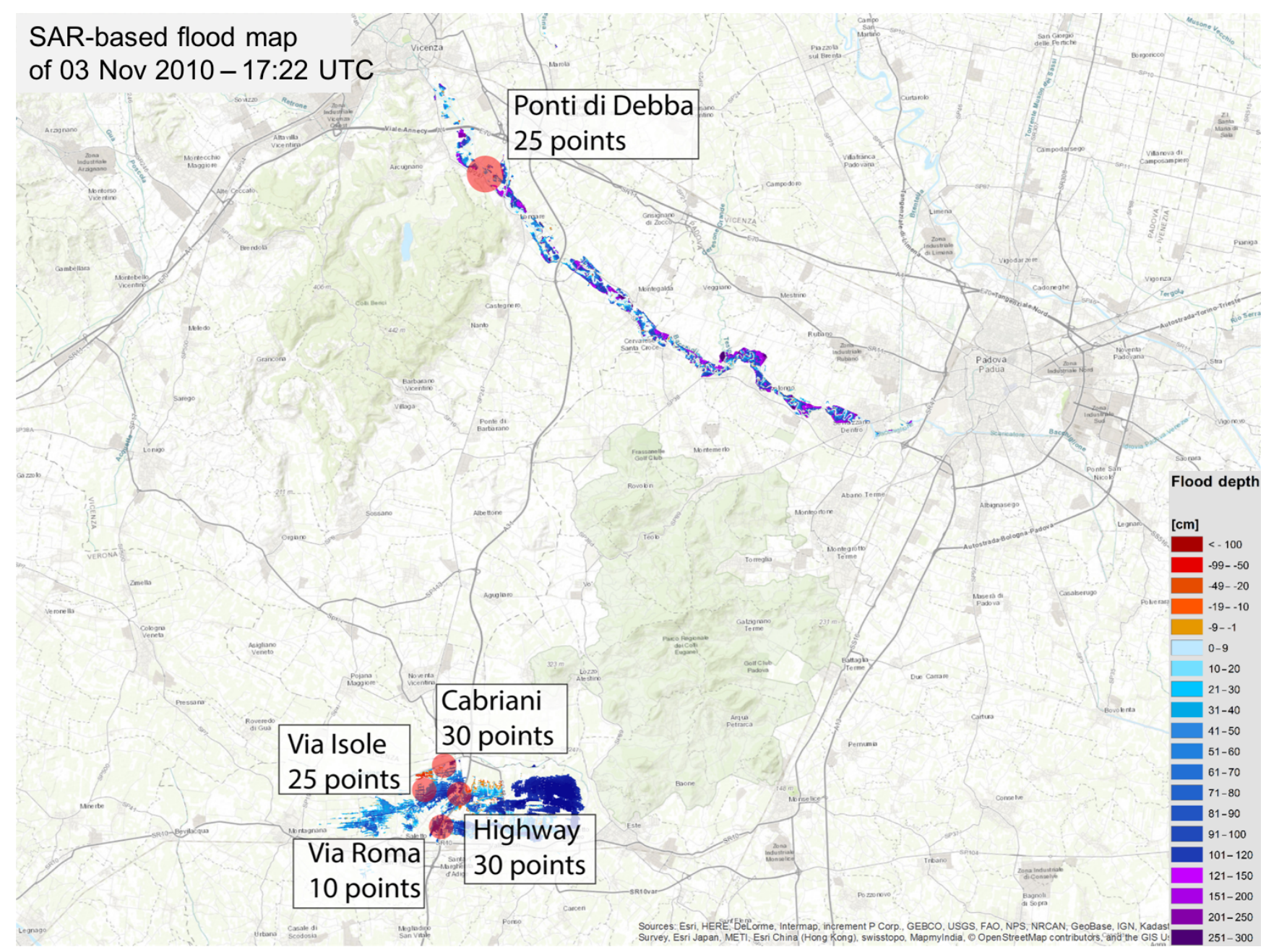

Figure 12. Distribution of the validation points selected for flood depth assessment: a total of 120 validation points collected in the Vicenza and Saletto areas (i.e., 25 and 95, respectively) have been selected based on recognizable features in the aerial and fieldwork photos available for 1 and 2 November. The reported SAR-based flood depth map used for the assessment refers to 3 November 2010.

Differences of two types can be seen between the two approaches: (i) different flood extent and (ii) different flood depth values between the model-based result and the SARbased one. Concerning the first type of difference, Fig. 14 shows the SAR image (a) from which the SAR-based flood extent (b) was derived and the flood extent derived by the hydrodynamic model (c). The red box in Fig. 14b and c delineates the boundary of the hydrodynamic modeling. From the comparison of these two extents, as well as the ones in Fig. 13, it is clear that the hydrodynamic model overestimates the flood extent compared to the SAR observation. This leads to the second type of difference, i.e., the different values of flood depth. A different extent leads to a different estimation of the water surface, which in turn can be different depending on the methodology employed and therefore provides a different flood depth value.

Analyzing the two results, differences in flood extents seem to be the main driver of discrepancies. In fact, gener- ally we can observe an overestimation of flood depth by the hydrodynamic model, which overestimates the flood extent. In the case of Veggiano on both dates (Fig. 13c and f), the difference is greater than $1 \mathrm{~m}$ only in a small portion of the image $\left(<0.3 \mathrm{~km}^{2}\right)$, while in the rest of the image the difference is mainly between 10 and $50 \mathrm{~cm}$. In the case of Bovolenta (Fig. 13i) the difference is bigger, with an area of about $1 \mathrm{~km}^{2}$ with a difference greater than $1 \mathrm{~m}$. In this case, we can also see an overestimation of depth by our method to the southeast of the flood, which is well below $1 \mathrm{~m}$ in almost all the cases.

Tables 2 and 3 confirm this analysis. In fact, Table 2 compares the flood extent obtained by the model with the one derived from the SAR image showing the area reported only by the model, only by the SAR-based approach, and the agreement between the two. If for the Veggiano area the difference between the two extents for both dates is limited to about $1 \mathrm{~km}^{2}$, in the Bovolenta area the difference is more 
Table 2. Flood extent cross comparison between SAR-based extent and hydrodynamic model-based extent.

\begin{tabular}{lrrr}
\hline Date - area & $\begin{array}{r}\text { Only hydrodynamic } \\
\text { model extent }\left(\mathrm{km}^{2}\right)\end{array}$ & $\begin{array}{r}\text { Only SAR-based } \\
\text { extent }\left(\mathrm{km}^{2}\right)\end{array}$ & $\begin{array}{r}\text { Agreement between } \\
\text { the two extents }\left(\mathrm{km}^{2}\right)\end{array}$ \\
\hline 3 November - Veggiano & 6.81 & 5.86 & 4.33 \\
4 November - Veggiano & 4.87 & 3.82 & 2.77 \\
4 November - Bovolenta & 15.63 & 8.48 & 7.98 \\
\hline
\end{tabular}

Table 3. Comparison between flood depth obtained with the hydrodynamic model and the proposed methodology.

\begin{tabular}{lrrr}
\hline Date - area & $\begin{array}{r}\text { Mean difference } \\
(\mathrm{cm})\end{array}$ & $\begin{array}{r}\text { Mean absolute } \\
\text { difference }(\mathrm{cm})\end{array}$ & $\begin{array}{r}\text { RMSD } \\
(\mathrm{cm})\end{array}$ \\
\hline 3 November - Veggiano & -27 & 42 & 55 \\
4 November - Veggiano & -63 & 68 & 73 \\
4 November - Bovolenta & -37 & 62 & 79 \\
\hline
\end{tabular}

consistent, about $7 \mathrm{~km}^{2}$; i.e., the model reports about 2 times the extent of the SAR observation. These numbers confirm the overestimation of the hydrodynamic model. The reasons for this difference can vary. On the one hand, areas reported as flooded in the simulation could have been in truth protected by barriers not taken into consideration by the model, hence leading to an overestimation of the simulated flood extent. On the other hand, the SAR-based maps might experience some underestimation in the presence of urban or vegetated flooded areas (where the radar backscattering might increases due to specific multiple bouncing).

Table 3 instead numerically compares the flood depth obtained with the two methods. The root-mean-square difference (RMSD) shows a value of $55 \mathrm{~cm}$ in the area of Veggiano on 3 November, $73 \mathrm{~cm}$ on 4 November, and $79 \mathrm{~cm}$ in the area of Bovolenta on 4 November. Once again, the numbers confirm the qualitative analysis and were expected given the overestimation of the flood extent by the model.

\section{Conclusions}

In this paper, we showed a methodology for assessing flood depth based on a statistical analysis of elevation data along the boundary lines of flooded areas. Starting from flood extent maps and using high-resolution DEM, water elevation can be estimated and therefore flood depth computed. The methodology may become suitable for operational mode. In fact, it meets the ideal requirements as indicated by Brown et al. (2016): accurate, simple to use also for non-Geographical Information System and remote sensing experts, easily applicable to different satellite data (SAR and optical), and quick to apply.

The results have been assessed through aerial and fieldwork images acquired during the event. The assessment, carried out on 120 pints distributed in the areas of Vicenza and Saletto, shows (i) an average underestimation of $53 \mathrm{~cm}$ for the area of Vicenza, due mainly to the decrease in water level from 1 November (date of aerial images) to 3 November (date of SAR acquisition), and (ii) an average overestimation of $47 \mathrm{~cm}$ for the area of Saletto, due mainly to the increase in water level from 1 November (date of aerial images) to 3 November (date of SAR acquisition) in this part of the flood.

In comparison with hydrodynamic models, this methodology is more easily implemented since less information is needed: a stack of SAR images (before and after the event) and a DEM. Hydrodynamic models need additional information, such as inflow discharges and values for roughness parameters, in order to derive depth and in case of a desired higher precision also precipitation data, information about the soil, number and location of water pumps, etc.

The comparison with results obtained with a hydrodynamic model gives relatively good correspondence, the main difference being the different flood extent estimated by the model, which leads to a generally higher depth estimation. The model shows less accuracy together with a more complex utilization due to the additional data required to run it.

However, it must be taken into consideration that satellite observations allow us to outline the flooded area and estimate the water depth at the specific date and time of their acquisition, which do not necessarily correspond to the maximum flood extent and water depth. If the images are acquired far from the flood peak (either before or after), the estimated extent and depth will underestimate the worst situation that occurred during the event.

In comparison to existing methodologies in the literature based on SAR data, the method we present is simple since it requires only the flood extent map and a DEM as inputs, it is based on an algorithm that does not require strong capacity in terms of computation and manual interaction, and it is able to handle the uncertainties of the SAR-based flood maps. 


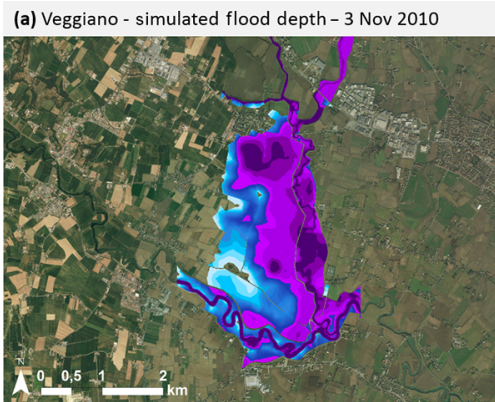

(b) Veggiano - SAR-based flood depth - 3 Nov 2010

(c) Veggiano - $\Delta$ Depth (Model-SAR-based) - 3 Nov 2010

(d) Veggiano - simulated flood depth - 4 Nov 2010
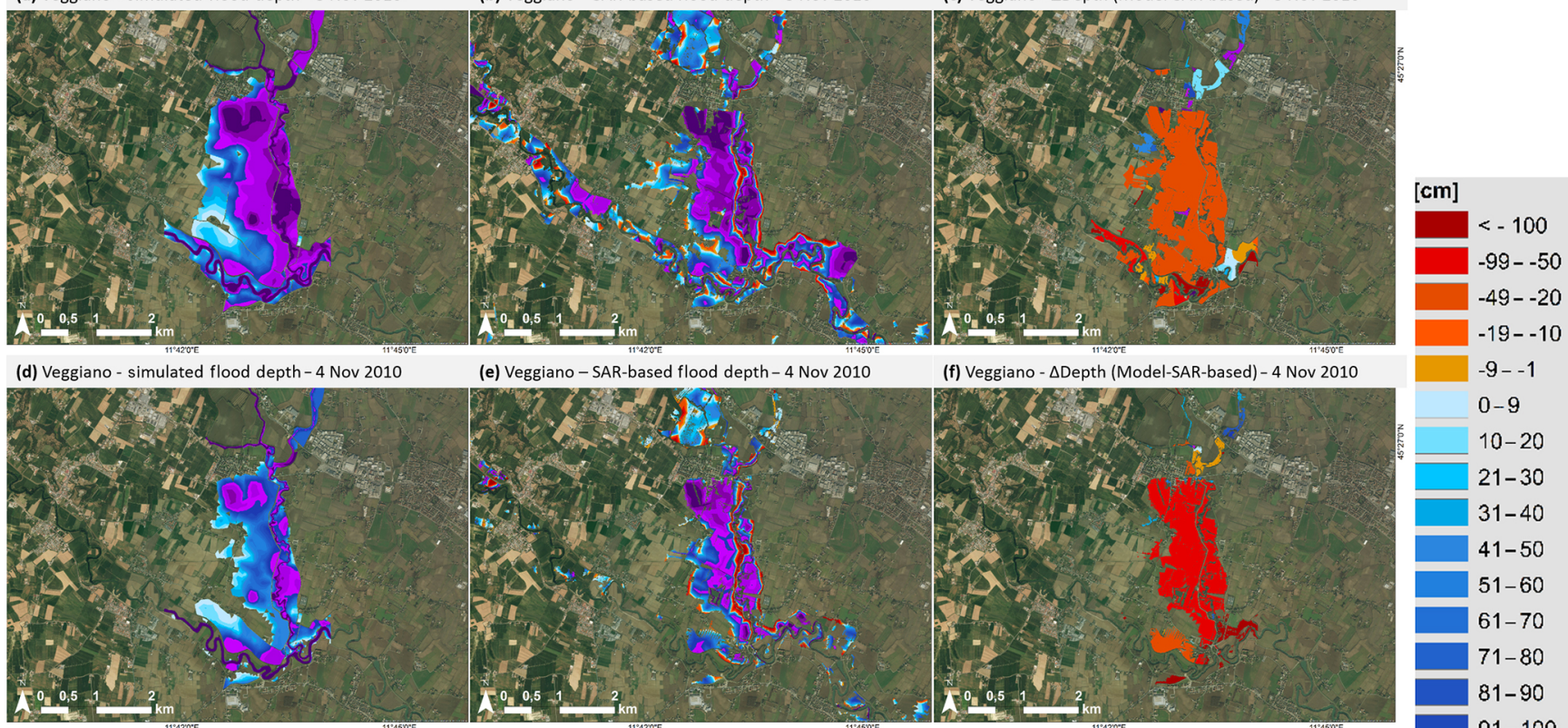

(e) Veggiano-SAR-based flood depth-4 Nov 2010

(f) Veggiano - $\triangle$ Depth (Model-SAR-based) - 4 Nov 2010

$-9--1$

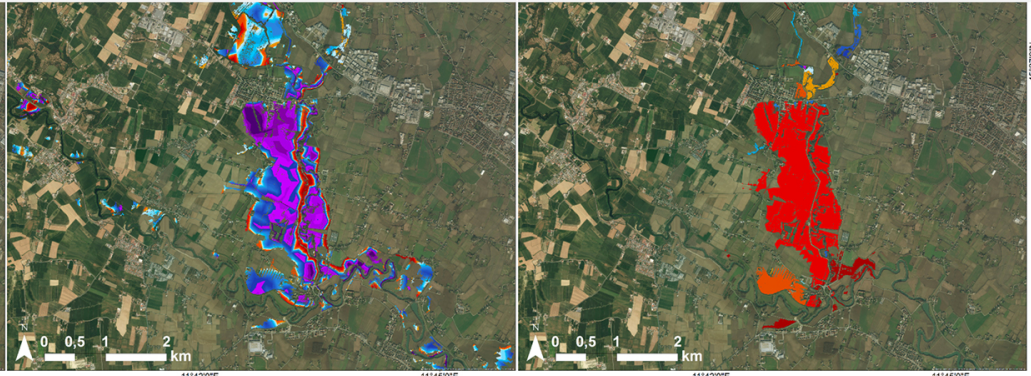

(g) Bovolenta - simulated flood depth- 4 Nov 2010

(h) Bovolenta - SAR-based flood depth - 4 Nov 2010

(i) Bovolenta - $\triangle$ Depth (Model-SAR-based) - 4 Nov 2010

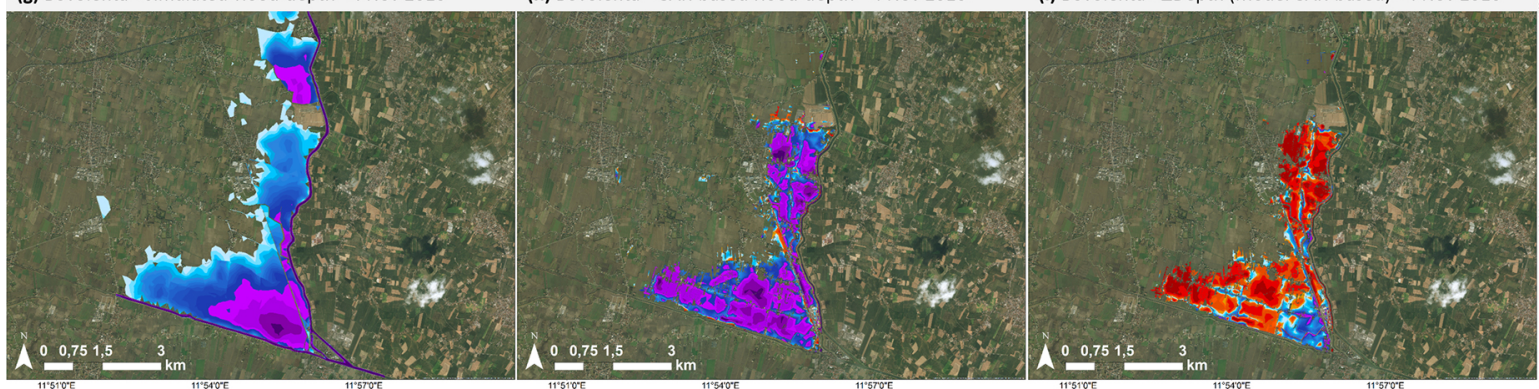

$0-9$

$10-20$

21- 30

$31-40$

41- 50

$51-60$

$61-70$

$71-80$

$81-90$

$91-100$

$101-120$

121-150

151-200

201-250

251-300

Figure 13. Comparison between the estimated flood extent and depth from the hydrodynamic model and the proposed system based on the same DTM at $5 \mathrm{~m}$ resolution. (a-c): simulated flood depth, SAR-based flood depth, and the difference between the two for the Veggiano area on 3 November; (d-f): simulated flood depth, SAR-based flood depth, and the difference between the two for the Veggiano area on 4 November; (g-i): simulated flood depth, SAR-based flood depth, and the difference between the two for the Bovolenta area on 4 November.

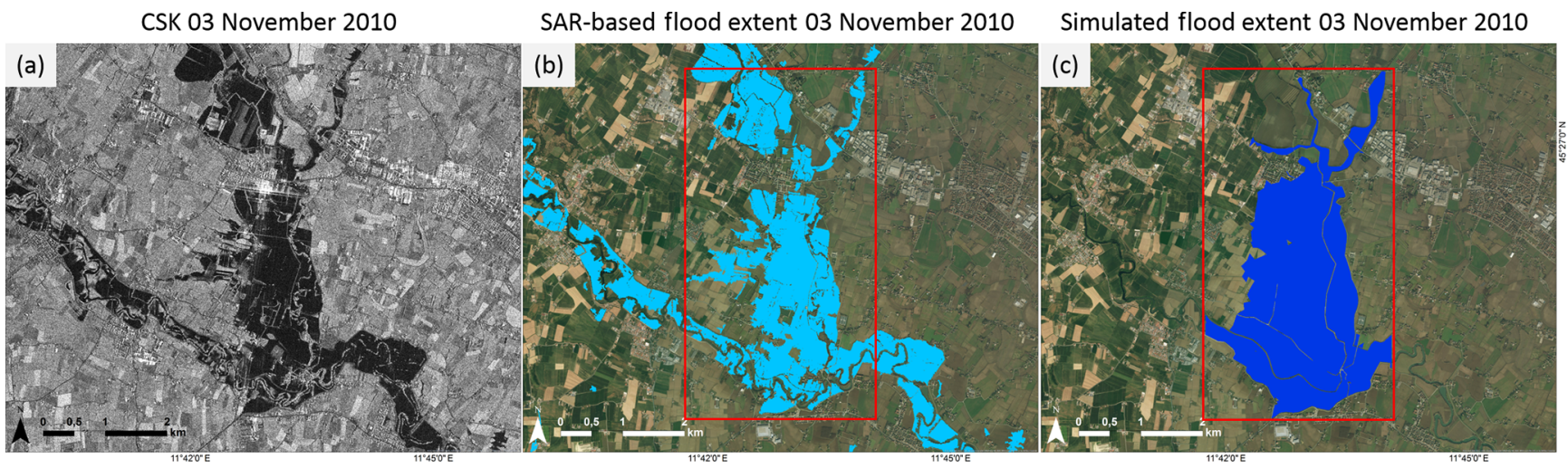

Figure 14. Comparison between SAR-based flood extent and simulated flood extent for the Veggiano area on 3 November. Panel (a) shows the CSK SAR image of 3 November 2010; panel (b) shows the flood extent derived from the SAR image; panel (c) shows the simulated flood extent, which was calculated only for the area delimited by the red box. The difference between the two extents is very clear. 
The proposed approach is based on the main hypothesis that water surfaces are flat and exhibit a constant elevation along their boundaries. This has been considered fair where the area affected by the flood is characterized by a flat terrain or a gentle slope and where the considered river and riverine flood show a slow dynamic.

The area under analysis in this study presents these characteristics and the obtained results proved to be particularly accurate, hence confirming the goodness of the abovementioned assumptions. However, the methodology, even though not suitable to be applied in the presence of steeper terrain or fast river and flood dynamic, allows us to identify where this occurs. Indeed, the statistical analysis of the terrain elevation at the boundary of the flooded areas detects when we are in the presence of pretty unstable distributions and, in such cases, the algorithm would produce a warning and prevent the computation of a wrong flood depth.

Furthermore, we also showed that in some cases, despite being true, the assumption of flat water does not find an actual correspondence in the data. For instance, we might not retrieve constant elevation values along the boundaries of flooded areas when there are errors in the initial SAR-based flood map (i.e., errors in the flood extent or misalignments of the SAR image and the DEM). However, making use of statistical analysis, we are able to handle these outlier values and to obtain results that proved accurate according to in situ measurements.

In addition to the employment of a detailed flood extent, a key requirement for obtaining reliable flood depth maps is the availability of accurate height information. Here, the proposed method supports DEMs at any spatial and vertical resolution; however, results may strongly vary depending on the specific dataset available. In particular, the access to a high-resolution DEM may be the discriminant for deciding whether to apply the technique or not. For example, for the original purpose for which we implemented the methodology (i.e., flood economic impact assessment), a high precision is required and a vertical resolution of $1 \mathrm{~m}$ may not be sufficient to precisely estimate the damages caused by a given flood. In fact, damage functions may already saturate at $2 \mathrm{~m}$; thus, if the estimated depth were $1 \mathrm{~m} \pm 1 \mathrm{~m}$, for example, then the resulting damage would have the same uncertainty that one can obtain without using our technique.

Finally, by treating each flooded area individually, the method is able to take into consideration the natural variation in water elevation of a river, due to its slope, possible asymmetries of riverbanks and river flow, and floodplain dynamics, which can cause different flood conditions at the two sides of the river.

Despite the very good results obtained, the methodology can be further improved and automatized. Future work may consider integrating a DEM filling procedure for improving water level estimation (Huang et al., 2014). The use of a vegetation index such as NDVI could exclude wrong points along the boundary lines. In fact, if vegetation is found along the boundary, it may indicate an error in the flood map and therefore the correspondent elevation would be information to be discarded. Similarly, slope can be computed from the DEM and used to exclude errors due to radar shadow or misalignment between SAR and DEM data. In fact, if the elevation measured is greater than a certain threshold, it may indicate that the point is on a steep area (e.g., river banks) and has a high probability that the point was wrongly included in the flood map (radar shadow), or the pixel in the flood map does not exactly overlap the DEM. Excluding these possible sources of error would improve the statistics and therefore the estimation of the water level.

Moreover, shallow water in short vegetation could be mapped (Cian et al., 2018) and used to improve the SARbased flood map from the omission errors caused by vegetation.

Another improvement may come from the method for creating the water elevation plane. Instead of relying simply on the elevation value distribution, the plane that minimizes the RMSE could be found using the points on the boundary line left after the exclusion of outliers. The plane created could also take into consideration the slope of the river in a better way compared to the current method. By means of a shape index and the relative position between the river and the flooded area, the slope of the polygons can be estimated and imposed on the water plane. This would take into account the slope of the river and therefore the dynamics of the flood, allowing us to also derive better results for floods with a fast dynamic.

In conclusion, the proposed methodology shows great potential in support of rapid economic flood damage assessment. In fact, being able to rapidly estimate the flood depth allows the computation of economic damage using available damage functions, which given a certain flood depth, returns the percentage of damage suffered by the economic asset considered. The precise estimation of flood depth value increases the accuracy of the estimation of a flood impact, which is extremely important in the emergency response phase of a disaster.

Data availability. SAR images used for this research are not publicly available. They can be accessed through the Italian Space Agency end e-GEOS. The digital elevation models employed in this research are accessible through the geo-database of the Veneto region (DTM $5 \mathrm{~m}$ ) and by requesting them from the Italian Ministry of the Environment (lidar at $1 \mathrm{~m}$ ) and the Venice Water Authority (lidar at $2 \mathrm{~m}$ ).

Author contributions. FC and MM designed the methodology. FC developed the methodology with the support of MM and PC. CG supported the analysis of results. FC and MM wrote the manuscript. $\mathrm{PC}$ and $\mathrm{CG}$ revised the manuscript. 
Competing interests. The authors declare that they have no conflict of interest.

Acknowledgements. The authors would like to thank the Italian Space Agency (ASI), which provided the SAR data for producing the flood maps, Annekatrin Metz, German Aerospace Center, who provided support in writing the script in Python, Daniele Pietro Viero, University of Padua, who kindly provided the hydrodynamic modeling of the event and support in evaluating our results, and Michele Martone, German Aerospace Center, for the precious comments and suggestions that helped improve this work.

Edited by: Kai Schröter

Reviewed by: two anonymous referees

\section{References}

Amadio, M., Mysiak, J., Carrera, L., and Koks, E.: Improving flood damage assessment models in Italy, Nat. Hazards, 82, 1-14, https://doi.org/10.1007/s11069-016-2286-0, 2016.

ArcPy: "What is ArcPy?", http://pro.arcgis.com/en/proapp/arcpy/get-started/what-is-arcpy-.htm, last access: 15 November 2018.

ARPAV: Report of the "Agenzia Regionale Per la Prevenzione e Protezione Ambientale del Veneto" (ARPAV), Scheda Evento "Pluvio", (Figura 2), Veneto Region, 1-16, 2010.

Brown, K. M. and Brownett, J. M.: Progress in operational flood mapping using satellite synthetic aperture radar (SAR) and airborne light detection and ranging (LiDAR) data, 40, 196-214, https://doi.org/10.1177/0309133316633570, 2016.

Brisco, B., Schmitt, A., Murnaghan, K., Kaya, S., and Roth, A.: SAR polarimetric change detection for flooded vegetation, Int. J. Digit. Earth, 6, 1-12, 2011.

Carrera, L., Standardi, G., Bosello, F., and Mysiak, J.: Assessing direct and indirect economic impacts of a flood event through the integration of spatial and computable general equilibrium modelling, CMCC Research, 63, 1-27, https://doi.org/10.1016/j.envsoft.2014.09.016, 2013.

Chini, M., Pulvirenti, L., and Pierdicca, N.: Analysis and interpretation of the COSMO-SkyMed observations of the 2011 Japan tsunami, IEEE Geosci. Remote S., 9, 467-471, https://doi.org/10.1109/LGRS.2011.2182495, 2012.

Cian, F., Marconcini, M., and Ceccato, P.: Normalized Difference Flood Index for rapid flood mapping: Taking advantage of EO big data, Remote Sens. Environ., 209, 712-730, https://doi.org/10.1016/j.rse.2018.03.006, 2018.

Cohen, J.: Weighted kappa: Nominal scale agreement provision for scaled disagreement or partial credit, Psychol. Bull., 70, 213220, 1968

Copernicus EMS: Copernicus Emergency Management Service, available at: http://emergency.copernicus.eu/mapping/ copernicus-emergency-management-service, last access: 15 November 2018.

Cohen, S., Brakenridge, G., Kettner, A., Bates, B., Nelson, J., McDonald, R., Huang, Y. F., Munasinghe, D., and Zhang, J.: Estimating Floodwater Depths from Flood Inundation Maps and Topography, J. Am. Water Resour. As., 54, 847-858, https://doi.org/10.1111/1752-1688.12609, 2018.

Cossu, R., Schoepfer, E., Bally, P., and Fusco, L.: Near real-time SAR-based processing to support flood monitoring, J. Real-Time Image Process., 4, 205-218, 2009.

D’Alpaos, L., Brath, A., and Fioravante, V.: Relazione tecnicoscientifica sulle cause del collasso dell' argine del fiume Secchia avvenuto il giorno 19 gennaio 2014 presso la frazione San Matteo, Report of the Emilia-Romagna Region, 2014.

Dasgupta, A., Grimaldi, S., Ramsankaran, R. A. A. J., Pauwels, V. R. N., and Walker, J. P.: Towards operational SAR-based flood mapping using neuro-fuzzy texturebased approaches, Remote Sens. Environ., 215, 313-329, https://doi.org/10.1016/j.rse.2018.06.019, 2018.

Desai, B., Maskrey, A., Peduzzi, P., De Bono, A., and Herold, C.: Making Development Sustainable: The Future of Disaster Risk Management, Global Assessment Report on Disaster Risk Reduction, United Nations Office for Disaster Risk Reduction (UNISDR), Genève, Suisse, 2015.

European Commission (EC): Directive 2010/31/EU of the European Parliament and of the Council, Off. J. Eur. Union, L 153/13, 18 June 2010, 288, 13-35, 2010.

Floris, M., D’Alpaos, A., De Agostini, A., Stevan, G., Tessari, G., and Genevois, R.: A process-based model for the definition of hydrological alert systems in landslide risk mitigation, Nat. Hazards Earth Syst. Sci., 12, 3343-3357, https://doi.org/10.5194/nhess12-3343-2012, 2012.

Franceschetti, G. and Lunari, R.: Synthetic Aperture Radar Processing, CRC press, Boca Raton, 2018.

Giordan, D., Notti, D., Villa, A., Zucca, F., Calò, F., Pepe, A., Dutto, F., Pari, P., Baldo, M., and Allasia, P.: Low cost, multiscale and multi-sensor application for flooded area mapping, Nat. Hazards Earth Syst. Sci., 18, 1493-1516, https://doi.org/10.5194/nhess18-1493-2018, 2018.

Giustarini, L., Hostache, R., Matgen, P., Schumann, G. J., Bates, P. D., and Mason, D. C.: A Change Detection Approach to Flood Mapping in Urban Areas Using TerraSAR-X, IEEE T. Geosci. Remote, 51, 2417-2430, https://doi.org/10.1109/TGRS.2012.2210901, 2013.

Giustarini, L., Vernieuwe, H., Verwaeren, J., Chini, M., Hostache, R., Matgen, P., Verhoest N. E. C., and De Baets, B.: Accounting for image uncertainty in SAR-based flood mapping, Int. J. Appl. Earth Obs., 34, 70-77, https://doi.org/10.1016/j.jag.2014.06.017, 2015.

Gupta, R. P. and Banerji, S.: Monitoring of reservoir volume using LANDSAT data, J. Hydrol., 77, 159-170, https://doi.org/10.1016/0022-1694(85)90204-5, 1985.

Henry, J. B., Chastanet, P., Fellah, K., and Desnos, Y. L.: Envisat multi-polarized ASAR data for flood mapping, Int. J. Remote Sens., 27, 1921-1929, https://doi.org/10.1080/01431160500486724, 2006.

Horritt, M. S., Mason, D. C., and Luckman, A. J.: Flood boundary delineation from Synthetic Aperture Radar imagery using a statistical active contour model, Int. J. Remote Sens., 22, 24892507, 2001.

Huang, C., Chen, Y., Wu, J., Chen, Z., Li, L., Liu, R., and $\mathrm{Yu}, \mathrm{J}$.: Integration of remotely sensed inundation extent and high-precision topographic data for mapping inundation depth, The 3rd International Conference on Agro- 
Geoinformatics, Agro-Geoinformatics 2014, Beijing, China, 14, https://doi.org/10.1109/Agro-Geoinformatics.2014.6910580, 2014.

Iervolino, P., Guida, R., Iodice, A., and Riccio, D.: Flooding water depth estimation with high-resolution SAR, IEEE Trans. Geosci. Remote Sens., 53, 2295-2307, 2015.

International Charter: International Charter on Space and Major Disasters, available at: https://www.disasterscharter.org, last access: 15 November 2018.

Long, S., Fatoyinbo, T. E., and Policelli, F.: Flood extent mapping for Namibia using change detection and thresholding with SAR, Environ. Res. Lett., 9, 035002, https://doi.org/10.1088/17489326/9/3/035002, 2014.

Martinis, S., Twele, A., and Voigt, S.: Towards operational near real-time flood detection using a split-based automatic thresholding procedure on high resolution TerraSAR-X data, Nat. Hazards Earth Syst. Sci., 9, 303-314, https://doi.org/10.5194/nhess9-303-2009, 2009.

Martinis, S., Kersten, J., and Twele, A.: A fully automated TerraSAR-X based flood service, ISPRS J. Photogramm., 104, 203-212, https://doi.org/10.1016/j.isprsjprs.2014.07.014, 2015.

Mason, D. C., Davenport, I. J., Flather, R. A., Gurney, C., Robinson, G. J., and Smith, J. A.: A Sensitivity Analysis of the Waterline Method of Constructing a Digital Elevation Model for Intertidal Areas in ERS SAR scene of Eastern England, Estuar. Coast. Shelf S., 53, 759-778, https://doi.org/10.1006/ecss.2000.0789, 2001.

Matgen, P., Schumann, G., Henry, J.-B., Hoffmann, L., and Pfister, L.: Integration of SAR-derived river inundation areas, highprecision topographic data and a river flow model toward near real-time flood management, Int. J. Appl. Earth Obs., 9, 247263, https://doi.org/10.1016/j.jag.2006.03.003, 2007.

Matgen, P., Giustarini, L., Chini, M., Hostache, R., Wood, M., and Schlaffer, S.: Creating a water depth map from SAR flood extent and topography data, Int. Geosci. Remote Se., November 2016, 7635-7638, https://doi.org/10.1109/IGARSS.2016.7730991, 2016.

Mojtahed, V., Giupponi, C., Biscaro, C., Gain, A. K., and Balbi, S.: Integrated Assessment of Natural Hazards and Climate Change Adaptation: II, The SERRA Methodology, 7, 1-47, 2013.

Mysiak, J., Luther, J., and Vanneuville, W.: Towards a potential European flood impact database, EEA JRC ETC/CCA Joint Technical Paper, European Environment Agency, Bologna, 40, 2013.

NatCatSERVICE: Annual statistics 2014, Loss events worldwide 2014, Percentage distribution, Munich Re, Munich, Germany, 2015.

Nico, G., Pappalepore, M., Pasquariello, G., Refice, A., and Samarelli, S.: Comparison of SAR amplitude vs. coherence flood detection methods - a GIS application, Int. J. Remote Sens., 21, 1619-1631, https://doi.org/10.1080/014311600209931, 2000.

Oberstadler, R., Hönsch, H., and Huth, D.: Assessment of the mapping capabilities of ERS-1 SAR data for flood mapping: A case study in Germany, European Space Agency, (Special Publication) ESA SP, 11, 247-252, https://doi.org/10.1002/(SICI)10991085(199708)11:10<1415::AID-HYP532>3.0.CO;2-2, 1996.
O'Grady, D., Leblanc, M., and Gillieson, D.: Use of ENVISAT ASAR Global Monitoring Mode to complement optical data in the mapping of rapid broad-scale flooding in Pakistan, Hydrol. Earth Syst. Sci., 15, 3475-3494, https://doi.org/10.5194/hess-153475-2011, 2011.

Pierdicca, N., Pulvirenti, L., Chini, M., Guerriero, L., and Candela, L.: Observing floods from space: Experience gained from COSMO-SkyMed observations, Acta Astronaut., 84, 122-133, https://doi.org/10.1016/j.actaastro.2012.10.034, 2013.

Pierdicca, N., Pulvirenti, L., and Chini, M.: Flood Mapping in Vegetated and Urban Areas and Other Challenges: Models and Methods, in: Flood Monitoring through Remote Sensing, edited by: Refice, A., D'Addabbo, A., and Capolongo, D., Springer Remote Sensing/Photogrammetry, Springer, Cham, 135-179, https://doi.org/10.1007/978-3-319-63959-8_7, 2018.

Schumann, G., Hostache, R., Puech, C., Hoffmann, L., Matgen, P., Pappenberger, F., and Pfister, L.: High-resolution 3D flood information from radar imagery for flood hazard management, IEEE T. Geosci. Remote S., 45, 1715-1725, https://doi.org/10.1109/TGRS.2006.888103, 2007.

Schumann, G., Matgen, P., Cutler, M. E. J., Black, A., Hoffmann, L., and Pfister, L.: Comparison of remotely sensed water stages from LiDAR, topographic contours and SRTM, ISPRS J. Photogramm., 63, 283-296, https://doi.org/10.1016/j.isprsjprs.2007.09.004, 2008.

Schumann, G. J., Neal, J. C., Mason, D. C., and Bates, P. D.: The accuracy of sequential aerial photography and SAR data for observing urban flood dynamics. A case study of the UK summer 2007 floods, Remote Sens. Environ., 115, 2536-2546, https://doi.org/10.1016/j.rse.2011.04.039, 2011.

Scorzini, A. R. and Frank, E.: Flood damage curves: new insights from the 2010 flood in Veneto, Italy, J. Flood Risk. Manag., 10, 381-392, 2017.

Viero, D. Pietro, D'Alpaos, A., Carniello, L., and Defina, A.: Mathematical modeling of flooding due to river bank failure, Adv. Water Resour., 59, 82-94, https://doi.org/10.1016/j.advwatres.2013.05.011, 2013.

Viero, D. P., Peruzzo, P., Carniello, L., and Defina, A.: Integrated mathematical modeling of hydrological and hydrodynamic response to rainfall events in rural lowland catchments, Water Resour. Res., 50, 5941-5957, https://doi.org/10.1002/2013WR014293, 2014.

Zollo, A. L., Rillo, V., Bucchignani, E., Montesarchio, M., and Mercogliano, P.: Extreme temperature and precipitation events over Italy: Assessment of high-resolution simulations with COSMOCLM and future scenarios, Int. J. Climatol., 36, 987-1004, 2016.

Zwenzner, H. and Voigt, S.: Improved estimation of flood parameters by combining space based SAR data with very high resolution digital elevation data, Hydrol. Earth Syst. Sci., 13, 567-576, https://doi.org/10.5194/hess-13-567-2009, 2009. 